\title{
Joint Decision on Ordering and Pricing of Cruise Tourism Supply Chain with Competing Newsboy-Type Retailers
}

\author{
Miaoqing Shi and Bin Liu \\ School of Economics and Management, Shanghai Maritime University, Shanghai 201306, China \\ Correspondence should be addressed to Bin Liu; liubin@shmtu.edu.cn \\ Received 21 May 2018; Revised 15 June 2018; Accepted 28 June 2018; Published 26 July 2018 \\ Academic Editor: Honglei Xu
}

Copyright (C) 2018 Miaoqing Shi and Bin Liu. This is an open access article distributed under the Creative Commons Attribution License, which permits unrestricted use, distribution, and reproduction in any medium, provided the original work is properly cited.

Cruise industry has recorded rapid expansion during the last decades, and it has substantial contribution to local economies. In this paper, we introduce a cruise tourism supply chain system consisting of one supplier and two newsboy-type retailers. We investigate the optimal decisions in a decentralized system from a game theoretical perspective and find out the optimal ordering and pricing strategies of both retailers and the optimal wholesale prices of the supplier with the limited number of cruise tickets and try to find out how the total profits should be allocated by the two retailers in the alliance case. Our framework involves two operational strategies, including inconsistent wholesale prices in the benchmark case and consistent wholesale price in the alliance case in which the two retailers have a virtual alliance, combining to one retailer. A numerical example compares the performance of the supply chain members and the system in two cases and finds that it is better for the two retailers to have a virtual alliance, combining to one retailer when the total amount of cruise tickets ordered by the two retailers is constrained by the total number of cruise tickets for the supplier, but it is not good choice for the two retailers to combine to one retailer when the total number of cruise tickets for the supplier does not constrain the total amount of cruise tickets ordered by the two retailers. In addition, the performance of the system in the alliance case is as good as that in the benchmark case when the total amount of cruise tickets ordered by the two retailers is constrained by the total number of cruise tickets for the supplier. However, when the total number of cruise tickets for the supplier does not constrain the total amount of cruise tickets ordered by the two retailers, the performance of the system in the benchmark case is better than that in the alliance case.

\section{Introduction}

In recent years, we have witnessed a period of rapid growth and remarkable change in the cruise industry, which is one of the fastest growing and most dynamic segments of the entire tourism and leisure travel market $[1,2]$. According to Cruise Market Watch, the number of passengers is projected to grow to 25 million in 2019 with an average growth rate of $4.5 \%$ [3]. The substantial spending of cruise passengers, together with the high growth rates, indicates that the cruise industry has great market potential. Therefore, policy makers and researchers have paid close attention to the economic impacts of cruise tourism at the national or regional level [4], Chang and Lee et al. [3] build a network DEA model to elaborate the operation of cruise lines at two stages for the purpose of analyzing the financial statements of the lines. However, we investigate the supply chain management problem of the cruise industry in China.

In terms of the cruise industry, it may be different from the other industries in several ways. First, there is no salvage of the cruise tickets in one trip, but many products such as garment and mobile phone often have salvage after a period. Second, there is a nature partnership between the downstream retailers. That is when one retailer's order quantity of cruise tickets is less than the customers demand then they can reorder the cruise tickets from the other retailer by a higher reorder cost, which is similar to the emergency procurement behavior in Zhang and Liu [5]. But it is uncommon in other industries, because there always only exist competition between retailers in general case; that is, there is no specific cooperation between retailers. Third, because of the characteristics of cruise industry operation, 
there is almost no centralized system in the cruise industry. Suppliers and retailers compete with each other, while other industries may have centralized systems. Finally, the total number of cruise tickets for the supplier is fixed over a relatively long time, because the size of the cruise is fixed, and the number of cruise beds is limited, and it may hold a limited number of customers during one trip. It is impossible for the supplier to satisfy the total amount of cruise tickets ordered by downstream retailers when the total number of cruise tickets for the supplier is smaller than the total amount of cruise tickets ordered by retailers. But, for the other industries, it may always occur that the supplier can satisfy the total amount ordered by the retailers, and one can take no account of the limited number of products for the supplier.

Supply chain management has been studied by many researchers; however, it always refers to ordinary products, seasonal products, or other related products. These products often involve the passing of property, but the sale of cruise tickets may more involve the right of use to the cruise in one trip. That may be a difference between the cruise tourism supply chain management problem and other industries supply chain management issues. In addition, as for the two-echelon cruise tourism supply chain, there will always be competition between the upstream supplier and the downstream retailers like other industries supply chain, and, in reality, the competing retailers in the cruise industry can use alliance to counter the monopoly of supplier, and the paper considers the strategic alliance between the two retailers whether being better off to both retailers or not, and correspondingly we analyze the performance difference of the supplier and the system between the benchmark (without alliance) case and the alliance case.

In this paper, we address the cruise tourism supply chain consisting of one supplier-cruise owner and two competing retailers with the limited number of cruise tickets for the supplier under stochastic demand, and we find that the maximum profit function of the supplier is continuous and concave, so the optimal solution to the wholesale ticket price of the supplier exists, and it is the one and only solution; the maximum expected profit functions of both retailers are also continuous and concave, and the optimal solutions to the retail ticket price and order quantity of cruise tickets for both retailers exist, and that is the one and only solution, and then this paper illustrates that the optimal wholesale ticket price of the supplier is not affected by the market potentials of both retailers in the alliance case; that is, the optimal wholesale ticket price in the alliance case is decided by supplier without considering the market potential of both retailers or the market potential gap between the two retailers. We are particularly interested to see what the performance difference of the supply chain members and the system is between in the benchmark scenario and in the alliance scenario with a certain number of cruise tickets for the supplier, and we study the optimal decisions of the supplier and both retailers in the two scenarios. Furthermore, the paper numerically investigates the impacts of related parameters on the supplier's profit, the two retailers' expected profits, the system's expected profit, the optimal pricing and ordering decisions of both retailers, and the optimal pricing decision of the supplier. In addition, our work considers the profits allocation between the two retailers in the alliance case, and the paper gives some useful management insights into the economic behaviors of cruise firms. We assume that all parameters and states are considered common knowledge so that all players have full information [6], and when each of the two retailers has no enough number of cruise tickets to customers, the retailer can reorder the insufficient number of cruise tickets using more than the wholesale price costs from the other retailer. The two retailers are in the same market and compete with each other in the benchmark case, and the two retailers cooperate to have a virtual alliance, combining to one retailer to weaken the supplier's monopoly position in the alliance case.

The relevant literature can be divided into three research streams: joint decision on pricing and ordering research, multiechelon supply chain research, and competitive research. The newsvendor model is necessitated by the pricing and ordering decisions under uncertain demand. And our work is closely related to the newsvendor setting literature. Whitin [7] is the first to formulate a newsvendor model with price effects. In his model, selling price and stocking quantity are set simultaneously. Petruzzi and Dada [8] review the newsvendor problem and formulate a randomness in demand which is price independent model either in an additive or in a multiplicative fashion. Hua and Wang et al. [9] consider the newsvendor problem that incorporates price decision with free shipping using the two fashions.

In the operations management research, joint decision pricing and ordering research is not uncommon. Fu and Dan et al. [10] present a joint decisions model in a newsvendor setting, where a retailer sells the seasonal products at the weather-dependent prices and provide a detailed analysis of the problems and characterizations of the optimal decisions when the retailer is risk-neutral. Wu and Zhang [11] study ordering and pricing problems for new repeat-purchase products and incorporate the repeat-purchase rate and price effects into the Bass model to characterize the demand pattern which considers two decision models: two-stage decision model and joint decision model. Liu and Zhang et al. [12] investigate online dual channel supply chain system and its joint decision on production and pricing under information asymmetry. They extend a newsvendor framework to dual channel in which there exists competitions and apply the competitive stochastic customer demand functions to the dual channel supply chain management.

Because the overall system sometimes should be considered in the supply management, multiechelon supply chain is widely studied. Tiaojun and Gang et al. [13] study the coordination of the supply chain in which there are one manufacturer and two competing retailers with demand disruptions and consider a price-subsidy rate contract to coordinate the investments of the competing retailers with sales promotion opportunities and demand disruptions. Cachon and Zipkin [14] investigate a two-stage serial supply chain with stationary stochastic demand and fixed transportation times. Qi and Wang et al. [15] consider a two-echelon maketo-order supply chain consisting of one supplier and two retailers under carbon cap regulation and analyze the pricing 
decision process in a decentralized system from a game theoretical perspective.

Competitive research is challenging, but competition is also more in line with the actual situation, so many scholars study the optimization of supply chain from the perspective of competition. Parthasarathi and Sarmah et al. [16] study the supply chain coordination under retail competition using a newsvendor framework in which the random demand faced by each retailer is dependent on their own price as well as on the price of the competing retailer. In addition to this, the demand is also influenced by the initial stock level of each individual retailer. Bernstein and Federgruen [17] and Narayanan and Raman et al. [18] investigate decentralized supply chains with competing retailers under demand uncertainty and design contractual arrangements between the parties that allow the decentralized chain to perform as well as a centralized one. In addition, Liu and Zhang et al. [12] extend a newsvendor framework to dual channel in which there exists competitions and apply the competitive stochastic customer demand functions to the dual channel supply chain management, and Qi and Wang et al. [15] study a make-to-order supply chain with one supplier and two competing retailers under a carbon cap regulation and formulate different pricing models and analyze the respective pricing processes under a carbon cap regulation in a decentralized system considering the competition between the two retailers.

Our work is closely related to Qi and Wang et al. [15] but differs from Qi and Wang et al. [15] in several manners. First, the demand is deterministic of the two-echelon supply chain in their work, but our work studies the random demand. Second, they consider an external constraint-carbon cap regulation-imposed on the supply chain; however, our work considers the internal constraint of the limited number of cruise tickets for the supplier. Third, their framework involves various operational strategies, including consistent and inconsistent wholesale prices for the supplier and consistent and inconsistent retail prices for the two retailers, but our framework involves only two different pricing strategies, and we consider how the total expected profits of both retailers in the alliance case should be allocated by the two retailers, in which case both retailers launch an alliance against the monopoly position of the supplier in cruise industry. Our model is most closely related to Liu and Zhang et al. [12]; Liu and Zhang et al. [12] set a dual channel newsvendor model and investigate online dual channel supply chain system and its joint decision on production and pricing under information asymmetry; they take more consideration to the impact of information on retailer's optimal decisions and profits of the supplier and retailer. But our work has to consider the limited number of cruise tickets for the supplier.

This paper considers the limited number of cruise tickets for the supplier, and the two retailers may follow a policy which is similar to the "base-stock" policy. Federgruen and Zipkin [19] demonstrate that a modified base-stock policy is optimal for a single-stage capacitated inventory system over an infinite horizon; this policy recommends ordering up to a particular inventory level, if possible, but to the capacity level otherwise. And, in the optimal decisions process, similar to Ben Daya and Raouf [20] that develop a Lagrange based method for solving two-constraint problem with uniform demand distribution, we also solve the limited number of cruise tickets constraint problem using a Lagrange based method, and we develop a solution method based on KuhnTucker (K-T) conditions which produces the optimal solution to the problem with any continuous demand distribution similar to Zhang [21]. In addition, when the two retailers launch a virtual alliance, combining to one retailer in the alliance case, we establish a bargaining game similar to Selcuk and Gokpinar [22] in order to satisfy each of the both retailers.

The paper is structured as follows. In Section 2 we describe the model and provide some notations and assumptions. Section 3 solves the optimal decisions of the supplier and two retailers in the benchmark case. Section 4 deals with the optimal decisions of the supplier and two retailers in the alliance case as well as the total profits' allocation between the two retailers. Section 5, based on a numerical example, illustrates different optimal decisions under two cases and sensitivity to critical parameters, and it allows us to interpret the effects of market potential of the two retailers and competition between them on profits. We conclude in Section 6. Proofs appear in the Appendix.

\section{Modeling and Assumptions}

The paper considers a two-echelon supply chain consisting of one supplier and two retailers under stochastic demand with the limited number of cruise tickets for the supplier. Because, in the cruise industry, there are few cases of centralized system, then we discuss two cases (the benchmark case $W_{1} \neq$ $W_{2}$ and the alliance case $\left.W_{1}=W_{2}=W_{0}\right)$ in the decentralized system.

2.1. The Notations and Assumptions. For the stochastic customer demand, we denote the demand function of both retailers as follows:

$$
\begin{aligned}
D_{1}\left(P_{1}, P_{2}\right) & =y_{1}\left(P_{1}, P_{2}\right)+x_{1}, \\
y_{1}\left(P_{1}, P_{2}\right) & =\theta-P_{1}+\beta P_{2} . \\
\text { and } D_{2}\left(P_{1}, P_{2}\right) & =y_{2}\left(P_{1}, P_{2}\right)+x_{2}, \\
y_{2}\left(P_{1}, P_{2}\right) & =1-\theta-P_{2}+\beta P_{1} .
\end{aligned}
$$

$\theta$, which is a parameter, represents the market potential of retailer $r_{1} ; \beta$ is called the cross-price-sensitivity coefficient, which implies the intensity of competition between the two retailers, and $x_{i}$ is the random variable of retailer's $r_{i}(i=1,2)$ demand, with the mean $\mu_{i}(i=1,2)$, in our model, and let $\mu_{1}=\mu_{2}=0$ and the density function $f_{i}(\bullet)$ have a continuous derivative $f_{i}^{\prime}(\bullet)[16]$, and $f_{i}^{\prime}(\bullet) \geq 0$ in our model. The major notations used in this paper are listed in Table $\mathbf{1 .}$

Consistent with Petruzzi and Dada [8], we define

$$
\begin{aligned}
& z_{1}=Q_{1}-y_{1}\left(P_{1}, P_{2}\right), \\
& z_{2}=Q_{2}-y_{2}\left(P_{1}, P_{2}\right) .
\end{aligned}
$$


TABLE 1: Major notations.

\begin{tabular}{|c|c|}
\hline$c$ & The unit operating cost of the supplier \\
\hline$T_{0}$ & The total number of cruise tickets for the supplier \\
\hline$\theta$ & Market potential composed of the retailer $r_{1}$ \\
\hline$\beta$ & Cross price elastic coefficient \\
\hline$g$ & $\begin{array}{l}\text { The cost per unit when the amount of cruise tickets ordered by a retailer less than the demand of consumers } \\
\text { then to reorder from the other retailer }\end{array}$ \\
\hline$W_{i}$ & The unit wholesale ticket price of the supplier to retailer $r_{i}(i=1,2)$ in the benchmark case \\
\hline$W_{0}$ & The unit wholesale ticket price of the supplier to retailer $r_{i}(i=1,2)$ in the alliance case \\
\hline$P_{i}$ & The unit retail ticket price of the retailer $r_{i}(i=1,2)$ in the benchmark case \\
\hline$P_{i}^{\prime}$ & The unit retail ticket price of the retailer $r_{i}(i=1,2)$ in the alliance case \\
\hline$Q_{i}$ & The retailer $r_{i}^{\prime} s(i=1,2)$ order quantity of cruise tickets in the benchmark case \\
\hline$Q_{i}^{\prime}$ & The retailer $r_{i}^{\prime} s(i=1,2)$ order quantity of cruise tickets in the alliance case \\
\hline$\lambda$ & Lagrange multiplier in the benchmark case \\
\hline$\lambda^{\prime}$ & Lagrange multiplier in the alliance case \\
\hline$x_{i}$ & The random variable of retailer's $r_{i}(i=1,2)$ demand \\
\hline$f_{i}(\bullet)$ & The PDF(Probability Density Function) of random variable $x_{i}(i=1,2)$ \\
\hline$F_{i}(\bullet)$ & The CDF(Cumulative Distribution Function) of random variable $x_{i}(i=1,2)$ \\
\hline$F_{i}^{-1}(\bullet)$ & The inverse Cumulative Distribution Function of random variable $x_{i}(i=1,2)$ \\
\hline
\end{tabular}

Note: the subscripts " $r$ " and " $s$ " are added to the relative variables to represent the values of the retailer and supplier, respectively, the subscripts " 1 " and "2" are added to the relative variables to represent the values of the retailer $r_{1}$ and $r_{2}$ respectively, the subscript " $T$ " is added to the relative variables to represent the values of the system, and the superscripts " $*$ " and " '" are added to the relative variables to represent their corresponding optimal values and the corresponding values in the alliance case, respectively, and the expected profits in the benchmark case and the alliance case are denoted as $\Pi(\cdot), \Pi^{\prime}(\cdot)$, respectively.

$$
\begin{aligned}
& z_{1}^{\prime}=Q_{1}^{\prime}-y_{1}^{\prime}\left(P_{1}^{\prime}, P_{2}^{\prime}\right), \\
& z_{2}^{\prime}=Q_{2}^{\prime}-y_{2}^{\prime}\left(P_{1}^{\prime}, P_{2}^{\prime}\right) .
\end{aligned}
$$

where $Q_{i}(i=1,2)$ is the retailer's order quantity of cruise tickets in the benchmark case, and $Q^{\prime}{ }_{i}(i=1,2)$ is the retailer's order quantity of cruise tickets in the alliance case.

And there are also some assumptions made in our model.

(1) The total market potential equals 1 , and $\theta(\theta \in[0,1])$ represents the market potential of retailer $r_{1} .1-\theta$ represents the market potential of retailer $r_{2}$, and then we also assume that $\theta \geq 1 / 2$, implying that the market potential of the retailer $r_{1}$ is bigger than or equal to the market potential of the retailer $r_{2}$.

(2) The price-sensitivity coefficient of every retailer equals $\beta$, and $\beta<1(\beta \in[0,1])$, implying that the demand of retailer $r_{i}(i=1,2)$ is more sensitive to $P_{i}$ than the rival's price.

(3) $g>W_{i}>c(i=0,1,2)$, implying that the reorder cost when one retailer's order quantity of cruise tickets is less than the customers demand and then to order from the other retailer is larger than the wholesale ticket price from the supplier, and the wholesale ticket price of the supplier is larger than the operating cost of his own.

(4) The total number of cruise tickets levels at the beginning of the period. Both retailers know the total number of cruise tickets levels for the supplier at the beginning of the period, which was similarly assumed by Parker and Kapuściński [6].

(5) All the demands of customers must be met at all times, and the retailers must ensure satisfying the demands of customers through a cost which is larger than the wholesale ticket price and swift transportation from the other retailer to provide to customers $[5,12]$.

(6) All members in the cruise industry supply chain are risk-neutral. The market information is a common knowledge, and retailers are assumed to be operating in the same marketplace, and all of them seek the maximization of their own expected profit.

2.2. Modeling Formulation. In this paper, the supplier has a certain number of cruise tickets with a constant unit operating cost $c$, and the supplier determines the wholesale ticket prices to the two retailers. Both retailers operate in the same marketplace and compete with each other [6], and the two retailers, respectively, determine the retail ticket prices $P_{1}, P_{2}$ and the order quantities of cruise tickets $Q_{1}$, $Q_{2}$ simultaneously with the fixed number of cruise tickets $T_{0}$ for the supplier. We study a decentralized system in two cases, which are the benchmark case $\left(W_{1} \neq W_{2}\right)$ and the alliance case $\left(W_{1}=W_{2}=W_{0}\right)$, and we want to compare the performance of the supply chain members and the system between them in the benchmark case and in the alliance case where the two retailers have a virtual alliance, combining to one retailer. And the two-echelon cruise tourism supply chain is illustrated by Figure 1, where the benchmark case is represented in Figure 1(a) and the alliance case is represented in Figure 1(b).

We model the decisions process of the system as a Stackelberg game in which the supplier is the leader and the two retailers are the follower. In this system, the decisions process 


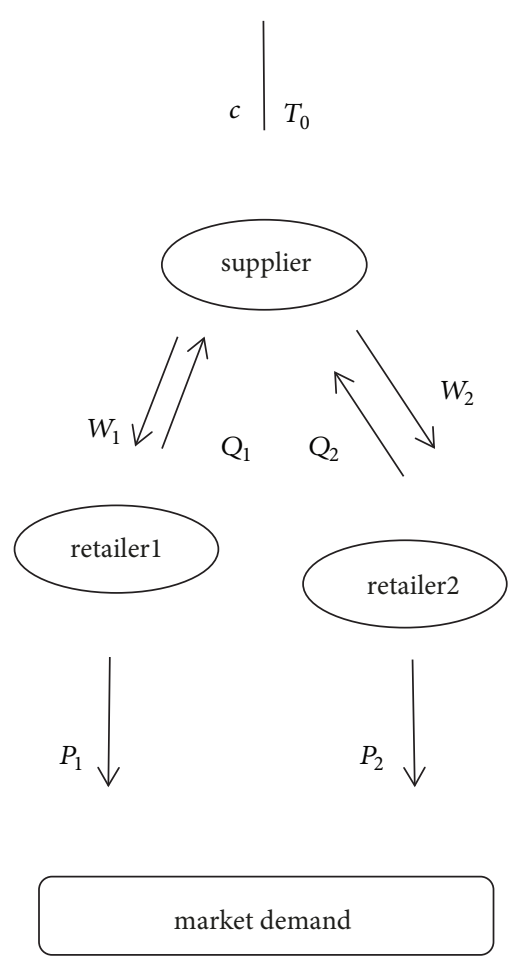

(a)

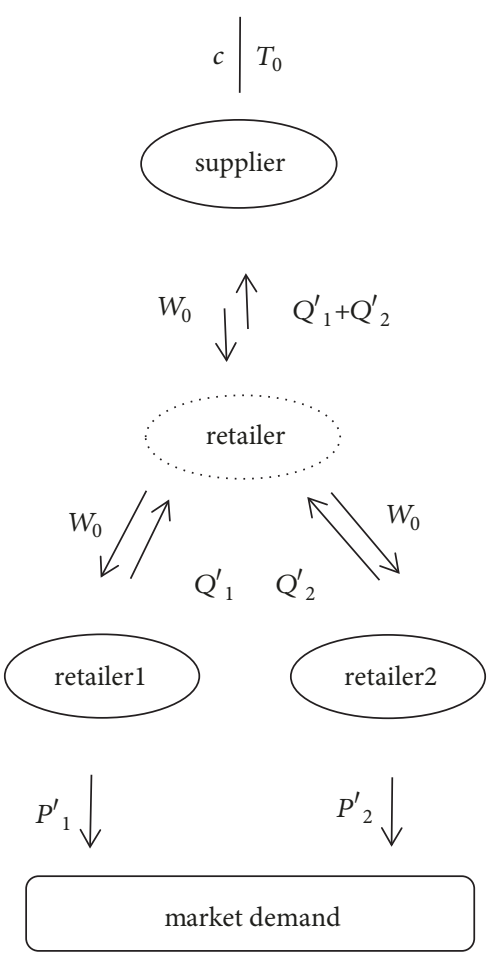

(b)

FIGURE 1: The two-echelon cruise tourism supply chain with one supplier and two retailers in two cases.

is that the supplier first determines the wholesale ticket prices $W_{1}$ and $W_{2}$ in the benchmark case or $W_{0}$ in the alliance case, and then the two retailers, respectively, determine their own retail ticket price and the order quantity of cruise tickets simultaneously. In addition, the cruise industry has no salvage value; then the model in the paper is equal to a model which is salvaged at 0 similar to Luo and Sethi et al. [23].

Under this system, the expected profit functions of both retailers in the benchmark case are

$$
\begin{gathered}
\Pi_{r i}\left(P_{i}, Q_{i}\right)=E\left(\pi\left(r_{i}\right)\right)=E\left(P_{i} * D_{i}\left(P_{1}, P_{2}\right)-W_{i}\right. \\
\left.* Q_{i}-g *\left[D_{i}\left(P_{1}, P_{2}\right)-Q_{i}\right]^{+}\right), \quad(i=1,2)
\end{gathered}
$$

where $[\bullet]^{+}=\max \{\bullet, 0\}$.

Given the retail ticket price and the order quantity of cruise tickets, the retailer's revenue is shown in the first term, the second term is the purchasing cost from the supplier, and the last term is the purchasing cost from the other retailer when the demand of consumers is larger than his/her orders.

The profit of the supplier in the benchmark case is

$$
\Pi_{s}\left(W_{1}, W_{2}\right)=W_{1} Q_{1}+W_{2} Q_{2}-c T_{0} .
$$

Accordingly, the expected profit functions of both retailers in the alliance case can be formulated by

$$
\begin{gathered}
\Pi_{r i}^{\prime}\left(P_{i}^{\prime} Q_{i}^{\prime}\right)=E\left(\pi^{\prime}\left(r_{i}\right)\right)=E\left(P_{i}^{\prime} * D_{i}\left(P^{\prime}{ }_{1}, P^{\prime}{ }_{2}\right)\right. \\
-W_{0} * Q_{i}^{\prime}-g *\left[D_{i}\left(P^{\prime}{ }_{1}, P^{\prime}{ }_{2}\right)-Q_{i}^{\prime}{ }_{i}{ }^{+}\right),
\end{gathered}
$$

The meaning of each term in this expression is similar to that in (5).

The profit of the supplier in the benchmark case can be formulated by

$$
\Pi_{s}^{\prime}\left(W_{0}\right)=W_{0}\left(Q_{1}^{\prime}+Q_{2}^{\prime}\right)-c T_{0} .
$$

The supplier and two retailers in two cases all operate to maximize their own expected profit.

\section{Optimal Joint Decisions in the Benchmark Case}

In this section, the supplier sets the wholesale price discrimination to the two retailers because of the different market potential of both retailers, and we use the backward sequential decision-making approach to obtain the optimal solutions.

3.1. Joint Decision on Pricing and Ordering of the Two Retailers in the Benchmark Case. From (1)-(5) and $\mu_{1}=\mu_{2}=0$, we can obtain the expected profit functions of both retailers in the benchmark case as follows:

$$
\begin{aligned}
\Pi r_{i}\left(P_{i}, z_{i}\right)= & P_{i} * y_{i}\left(P_{1}, P_{2}\right)-W_{i} *\left(y_{i}\left(P_{1}, P_{2}\right)+z_{i}\right) \\
& +g *\left(z_{i}-\Theta_{i}\left(z_{i}\right)\right), \quad(i=1,2)
\end{aligned}
$$

where $\Theta_{i}\left(z_{i}\right)=\int_{-a_{i}}^{z_{i}}\left(z_{i}-x_{i}\right) * f_{i}\left(x_{i}\right) d x_{i}(i=1,2)$.

We can formulate the Stackelberg game model under this system in the benchmark case as follows: 


$$
\begin{aligned}
\max _{\left(W_{1}, W_{2}\right)} & \Pi_{s}=W_{1} *\left(y_{1}\left(P_{1}^{*}, P_{2}^{*}\right)+z_{1}^{*}\right)+W_{2} *\left(y_{2}\left(P_{1}^{*}, P_{2}^{*}\right)+z_{2}^{*}\right)-c T_{0} \\
\text { s.t. } & y_{1}\left(P_{1}^{*}, P_{2}^{*}\right)+z_{1}^{*}+y_{2}\left(P_{1}^{*}, P_{2}^{*}\right)+z_{2}^{*} \leq T_{0} \\
& P_{1}^{*}, P_{2}^{*}, z_{1}^{*}, z_{2}^{*} \text { is derived from solving the following problem } \\
\max _{\left(P_{1}, z_{1}\right)} & \Pi_{r 1}=P_{1} * y_{1}\left(P_{1}, P_{2}\right)-W_{1} *\left(y_{1}\left(P_{1}, P_{2}\right)+z_{1}\right)+g *\left(z_{1}-\Theta_{1}\left(z_{1}\right)\right) \\
\max _{\left(P_{2}, z_{2}\right)} & \Pi_{r 2}=P_{2} * y_{2}\left(P_{1}, P_{2}\right)-W_{2} *\left(y_{2}\left(P_{1}, P_{2}\right)+z_{2}\right)+g *\left(z_{2}-\Theta_{2}\left(z_{2}\right)\right) .
\end{aligned}
$$

Using the backward sequential decision-making approach in this model, both retailers' response functions for the given wholesale prices $W_{1}$ and $W_{2}$ in the benchmark case may be obtained as follows:

$$
\begin{aligned}
P_{1}^{*}= & \frac{2 W_{1}+\beta W_{2}+\beta+(2-\beta) \theta}{4-\beta^{2}} \\
P_{2}^{*}= & \frac{2 W_{2}+\beta W_{1}+\beta+(2-\beta)(1-\theta)}{4-\beta^{2}} \\
Q_{1}^{*}= & \frac{\left(\beta^{2}-2\right) W_{1}+\beta W_{2}+\beta+(2-\beta) \theta}{4-\beta^{2}} \\
& +F_{1}^{-1}\left(\frac{g-W_{1}}{g}\right) \\
Q_{2}^{*}= & \frac{\left(\beta^{2}-2\right) W_{2}+\beta W_{1}+\beta+(2-\beta)(1-\theta)}{4-\beta^{2}} \\
& +F_{2}^{-1}\left(\frac{g-W_{2}}{g}\right) .
\end{aligned}
$$

From both retailers' response functions, we can obtain the following proposition.

Proposition 1. The retail ticket prices of both retailers are increasing with the increasing intensity of competition between the two retailers for the given values of $W_{1}$ and $W_{2}$.

Form Proposition 1, we know that the greater the competition between the two retailers, the larger the retail ticket prices of both retailers; that is, the retail ticket prices of both retailers are increasing with increasing the degree of the substitution between the two retailers.

3.2. Decision on Wholesale Ticket Prices of the Supplier in the Benchmark Case. Under this system, the supplier determines the optimal wholesale ticket prices $W_{1}^{*}$ and $W_{2}^{*}$ to the two retailers differently in the benchmark case based on the existing number of cruise tickets for the supplier. From the game model in the benchmark case we can have the following proposition.
Proposition 2. The optimal wholesale ticket prices of the supplier in the benchmark case can be given by

(i)

$$
\begin{aligned}
& {\left[1-f_{1} *\left(A_{1}-g\right)\right] W_{1}-f_{1} * F_{1}^{-1}\left(\frac{g-W_{1}}{g}\right)=0} \\
& {\left[1-f_{2} *\left(A_{2}-g\right)\right] W_{2}-f_{2} * F_{2}^{-1}\left(\frac{g-W_{2}}{g}\right)=0} \\
& \text { for } \lambda=0 .
\end{aligned}
$$

(ii)

$$
\begin{aligned}
& B_{2} W_{2}-B_{1} W_{1}+C_{2} g f_{2}-C_{1} g f_{1}=0 \\
& M T_{0}-N\left(W_{1}+W_{2}\right)-M E-S=0
\end{aligned}
$$

for $\lambda>0$

where $A_{1}=\left(\left(\beta^{2}-4 \beta\right) * \theta * g\right) /\left(\left(8-2 \beta^{2}\right)+\left(2 \beta^{2}+4 \beta-8-\right.\right.$ $\left.\left.\beta^{3}\right) \theta\right)-g, A_{2}=\left(\left(\beta^{2}-4 \beta\right) *(1-\theta) * g\right) /\left(\left(8-2 \beta^{2}\right)+\left(2 \beta^{2}+\right.\right.$ $\left.\left.4 \beta-8-\beta^{3}\right)(1-\theta)\right)-g$

$$
\begin{aligned}
& M=4-\beta^{2}, \\
& N=\beta^{2}+\beta-2, \\
& E=F_{1}^{-1}\left(\frac{g-W_{1}}{W_{1}}\right)+F_{2}^{-1}\left(\frac{g-W_{2}}{W_{2}}\right), \\
& S=2+\beta .
\end{aligned}
$$

Note that, in the rest of the paper, there always are $f_{i}=$ $f_{i}\left(F_{i}^{-1}\left(\left(g-W_{i}\right) / g\right)\right)$ and $f^{\prime}{ }_{i}=f^{\prime}{ }_{i}\left(F_{i}-1\left(\left(g-W_{i}\right) / g\right)\right)(i=1,2)$.

From Proposition 2, we can have the supplier's optimal wholesale ticket prices which may be different when the total number of cruise tickets for the supplier is different. To be more specific, the size relationship between the total amount of cruise tickets ordered by the two retailers and the total number of cruise tickets for the supplier may affect the optimal wholesale ticket prices of the supplier. 


\section{Optimal Joint Decisions in the Alliance Case}

In this section, the supplier decides the consistent wholesale price to the two retailers because there is an alliance between them, and then we also use the backward sequential decisionmaking approach to obtain the optimal solutions.

4.1. Joint Decision on Pricing and Ordering of the Two Retailers in the Alliance Case. From Section 2, we can have the expected profit functions of the two retailers in the alliance case as follows:

$$
\begin{aligned}
\Pi^{\prime} r_{i}\left(P_{i}^{\prime}, z_{i}^{\prime}\right)= & P_{i}^{\prime} * y_{i}^{\prime}\left(P_{1}^{\prime}, P_{2}^{\prime}\right)-W_{0} \\
& *\left(y_{i}^{\prime}\left(P_{1}^{\prime}, P_{2}^{\prime}\right)+z_{i}^{\prime}\right)+g \\
& *\left(z^{\prime}{ }_{i}-\Theta_{i}^{\prime}\left(z_{i}^{\prime}\right)\right), \quad(i=1,2) .
\end{aligned}
$$

where $\Theta_{i}^{\prime}\left(z_{i}^{\prime}\right)=\int_{-a_{i}}^{z^{\prime}}\left(z^{\prime}{ }_{i}-x_{i}\right) * f_{i}\left(x_{i}\right) d x_{i}(i=1,2)$.

Then we can formulate the Stackelberg game model under this system in the alliance case as follows:

$$
\begin{array}{cl}
\max _{W_{0}} & \Pi_{s}^{\prime}=W_{0} *\left(y_{1}^{\prime}\left(P_{1}^{\prime^{*}}, P_{2}^{\prime *}\right)+z_{1}^{\prime *}+y_{2}^{\prime}\left(P_{1}^{\prime *}, P_{2}^{\prime *}\right)+z_{2}^{\prime *}\right)-c T_{0} \\
\text { s.t. } & y_{1}^{\prime}\left(P_{1}^{\prime *}, P_{2}^{\prime *}\right)+z_{1}^{\prime *}+y_{2}^{\prime}\left(P_{1}^{\prime *}, P_{2}^{\prime *}\right)+z_{2}^{\prime *} \leq T_{0} \\
& P_{1}^{\prime *}, P_{2}^{\prime *}, z_{1}^{\prime *}, z_{2}^{\prime *} \text { is derived from solving the following problem } \\
\max _{\left(P_{1}^{\prime}, z_{1}^{\prime}\right)} & \Pi_{r 1}^{\prime}=P_{1}^{\prime} * y_{1}^{\prime}\left(P_{1}^{\prime}, P_{2}^{\prime}\right)-W_{0} *\left(y_{1}^{\prime}\left(P_{1}^{\prime}, P_{2}^{\prime}\right)+z_{1}^{\prime}\right)+g *\left(z_{1}^{\prime}-\Theta_{1}^{\prime}\left(z_{1}\right)\right) \\
\max _{\left(P_{2}^{\prime}, z_{2}^{\prime}\right)} & \Pi_{r 2}^{\prime}=P_{2}^{\prime} * y_{2}^{\prime}\left(P_{1}^{\prime}, P_{2}^{\prime}\right)-W_{0} *\left(y_{2}^{\prime}\left(P_{1}^{\prime}, P_{2}^{\prime}\right)+z_{2}^{\prime}\right)+g *\left(z_{2}^{\prime}-\Theta_{2}^{\prime}\left(z_{2}\right)\right) .
\end{array}
$$

The same as the structure in Section 3, we have both retailers' response functions in the alliance case as follows:

$$
\begin{aligned}
{P^{\prime}}_{1}^{*}= & \frac{(\beta+2) W_{0}+\beta+(2-\beta) \theta}{4-\beta^{2}} \\
P_{2}^{\prime *}= & \frac{(\beta+2) W_{0}+\beta+(2-\beta)(1-\theta)}{4-\beta^{2}} \\
Q_{1}^{\prime *}= & \frac{\left(\beta^{2}+\beta-2\right) W_{0}+\beta+(2-\beta) \theta}{4-\beta^{2}} \\
& +F_{1}^{-1}\left(\frac{g-W_{0}}{g}\right) \\
Q_{2}^{\prime *}= & \frac{\left(\beta^{2}+\beta-2\right) W_{0}+\beta+(2-\beta)(1-\theta)}{4-\beta^{2}} \\
& +F_{2}^{-1}\left(\frac{g-W_{0}}{g}\right) .
\end{aligned}
$$

4.2. Decision on Wholesale Ticket Price of the Supplier in the Alliance Case. Under this system, the supplier determines the optimal wholesale ticket price $W_{0}^{*}$ to the two retailers identically in the alliance case based on the existing number of cruise tickets, and, from the game model in the alliance case, we have the following proposition.

Proposition 3. The optimal wholesale ticket price of the supplier in the alliance case can be given by (i)

$$
\begin{aligned}
{\left[S^{\prime} M^{\prime}+(4 \beta-4) N^{\prime}\right] W_{0}-\left[S^{\prime} E^{\prime}-1\right] N^{\prime}=} & \\
& \text { for } \lambda=0 .
\end{aligned}
$$

(ii)

$$
W_{0}=\left(T_{0}-E^{\prime}\right) \frac{2-\beta}{2 \beta-2}-\frac{1}{2 \beta-2} \text { for } \lambda>0
$$

where $M^{\prime}=g\left(f_{1}+f_{2}\right), N^{\prime}=g^{2} f_{1} f_{2}, S^{\prime}=\beta-2$ and $E^{\prime}=$ $F_{1}^{-1}\left(\left(g-W_{0}\right) / g\right)+F_{2}^{-1}\left(\left(g-W_{0}\right) / g\right)$.

According to Proposition 3, we can obtain the following corollary.

Corollary 4. The optimal wholesale ticket price of the supplier in the alliance case is not affected by the market potential of the two retailers.

This corollary implies that the wholesale ticket price of the supplier to the two retailers in the alliance case has nothing to do with the market size of each retailer, and it may be related to the existing number of cruise tickets for the supplier and the competition between the two retailers.

4.3. Profits Allocation between the Two Retailers in the Alliance Case. In terms of the expected total profits size relationships of both retailers in the two cases, we can talk about it in two ways. In the first way, the total expected profits of the two retailers in the alliance case are equal to that in the benchmark case, and then the optimal negotiated payoff of the retailer in the alliance case equals the optimal expected profit of 
TABLE 2: The optimal solutions with different value of $\theta$ in the benchmark case.

\begin{tabular}{cccccccccc}
\hline$T_{0}$ & $\theta$ & $\beta$ & $W_{1}^{*}$ & $W_{2}^{*}$ & $P_{1}^{*}$ & $P_{2}^{*}$ & $Q_{1}^{*}$ \\
\hline 0.6 & 0.5 & 0.2 & 0.0797 & 0.0705 & 0.3216 & 0.3174 & 0.3231 \\
& 0.6 & & 0.0796 & 0.0708 & 0.3670 & 0.2721 & 0.3690 & 0.2305 \\
& 0.7 & & 0.0744 & 0.0865 & 0.4106 & 0.2343 & 0.4387 \\
0.5 & 0.8 & & 0.0792 & 0.0717 & 0.4578 & 0.1816 & 0.4618 & 0.1613 \\
& 0.5 & 0.2 & 0.0816 & 0.1336 & 0.3257 & 0.3494 & 0.3178 & 0.1822 \\
& 0.6 & & 0.0864 & 0.1187 & 0.3729 & 0.2966 & 0.3408 & 0.1592 \\
& 0.7 & & 0.0913 & 0.1036 & 0.4200 & 0.2438 & 0.3634 & 0.1366 \\
0.4 & 0.8 & & 0.0962 & 0.0885 & 0.4672 & 0.1910 & 0.3861 & 0.1139 \\
& 0.5 & 0.2 & 0.0985 & 0.1506 & 0.3351 & 0.3588 & 0.2425 & 0.1575 \\
& 0.6 & & 0.1034 & 0.1356 & 0.3823 & 0.3060 & 0.2652 & 0.1348 \\
& 0.7 & & 0.1083 & 0.1206 & 0.4295 & 0.2532 & 0.2879 & 0.1121 \\
& 0.8 & & 0.1132 & 0.1055 & 0.4766 & 0.2004 & 0.3106 \\
\hline
\end{tabular}

the retailer in the benchmark case. In the second way, the total expected profits of the two retailers in both cases are not equal, and there is a bargaining game between the two retailers in the alliance case.

Then, we can formulate a model which is similar to Selcuk and Gokpinar [22] in the alliance case as follows: let $\left(S_{1}, S_{2}\right)$ be the values of the expected profit of retailer $r_{1}$ and retailer $r_{2}$ in the bargaining game, and we have $S_{1}+S_{2}=\Pi_{r 1}^{\prime}+\Pi_{r 2}^{\prime}$; that is, $S_{2}=\Pi_{r 1}^{\prime}+\Pi_{r 2}^{\prime}-S_{1}$ and $S_{1}=\Pi_{r 1}^{\prime}+\Pi_{r 2}^{\prime}-S_{2}$.

We define the market potential of the retailer $r_{1}, \theta$, as the bargaining power of the retailer $r_{1}$, and we define $1-\theta$ as the bargaining power of the retailer $r_{2}$. Then the allocated value of the retailer $r_{1}, S_{1}$, can be found as the solution to the following maximization problem:

$$
\max _{S_{1} \in\left[0, \Pi_{r 1}^{\prime}+\Pi_{r 2}^{\prime}\right]}\left(S_{1}-\Pi_{r 1}\right)^{\theta}\left(\Pi_{r 1}^{\prime}+\Pi_{r 2}^{\prime}-S_{1}-\Pi_{r 2}\right)^{1-\theta} .
$$

The solution yields

$$
S_{1}^{*}=\theta\left(\Pi_{r 1}^{\prime}+\Pi_{r 2}^{\prime}\right)+(1-\theta) \Pi_{r 1}-\theta \Pi_{r 2} .
$$

Similarly, the allocated value of the retailer $r_{2}, S_{2}$, can be found as the solution to the following maximization problem:

$$
\max _{S_{2} \in\left[0, \Pi_{r 1}^{\prime}+\Pi_{r 2}^{\prime}\right]}\left(\Pi_{r 1}^{\prime}+\Pi_{r 2}^{\prime}-S_{2}-\Pi_{r 1}\right)^{\theta}\left(S_{2}-\Pi_{r 2}\right)^{1-\theta} .
$$

The solution yields

$$
S_{2}^{*}=(1-\theta)\left(\Pi_{r 1}^{\prime}+\Pi_{r 2}^{\prime}\right)+\theta \Pi_{r 2}-(1-\theta) \Pi_{r 1} .
$$

The optimal solution $S_{1}^{*}$ is the retailer $r_{1}$ 's payoff in the alliance case, and the optimal solution $S_{2}^{*}$ is the retailer $r_{2}$ 's payoff in the alliance case.

\section{Numerical Example}

In this section we provide a numerical example to illustrate the two cases in our model, and then we analyze the effects of the coefficients $\theta, \beta$ on the profits of the cruise supply chain members as well as the system and provide some management insights.
5.1. Numerical Analysis. In this subsection, we provide three different total numbers of cruise tickets for the supplier: $T_{0}=$ $0.6, T_{0}=0.5$, and $T_{0}=0.4$ and set the parameters as follows:

$$
\begin{aligned}
& c=0.005, \\
& g=0.2, \\
& \theta=0.6, \\
& \beta=0.2 .
\end{aligned}
$$

We give that $x_{i}(i=1,2)$ is uniformly distributed with a mean of 0 , respectively, which should satisfy the conditions that are given as the above, and then we set them as $x_{1} \sim$ $U_{1}[-0.4,0.4]$ and $x_{2} \sim U_{2}[-0.1,0.1]$.

The optimal solutions and the corresponding computational results in the benchmark case are summarized in Tables 2 and $\mathbf{3}$, and the optimal solutions and the corresponding computational results in the alliance case are summarized in Tables 4 and 5.

From Table 2, we can conclude that the optimal retail ticket price and the optimal order quantity of cruise tickets of the retailer $r_{1}$, which has the relatively larger market potential when $\theta>1 / 2$, are gradually increasing with the increasing $\theta$ whatever the total number of cruise tickets for the supplier is in the benchmark case. However, it is opposite to the retailer $r_{2}$, which has the smaller market potential and the retailer $\mathrm{r}_{2}$ 's optimal retail ticket price and the optimal order quantity of cruise tickets are decreasing with the increasing $\theta$ in the benchmark case with three different total numbers of cruise tickets for the supplier. Then we obtain the wholesale ticket prices change differently with three different total numbers of cruise tickets. First, when the total number of cruise tickets for the supplier equals 0.6 ; that is, the total number of cruise tickets for the supplier accounts for $60 \%$ of the total market demand, and when the total number of cruise tickets for the supplier does not constrain the total amount of cruise tickets ordered by both retailers, the optimal wholesale ticket price of the supplier to the retailer $r_{1}$ is slightly decreasing with the increasing $\theta$, but that to the retailer $r_{2}$ is slightly increasing with the increasing $\theta$, and the wholesale ticket price to the 
TABLE 3: The optimal solutions with different value of $\beta$ in the benchmark case.

\begin{tabular}{|c|c|c|c|c|c|c|c|c|}
\hline$T_{0}$ & $\theta$ & $\beta$ & $W_{1}^{*}$ & $W_{2}^{*}$ & $P_{1}^{*}$ & $P_{2}^{*}$ & $Q_{1}^{*}$ & $Q_{2}^{*}$ \\
\hline \multirow[t]{4}{*}{0.6} & 0.6 & 0.1 & 0.0798 & 0.0711 & 0.3526 & 0.2532 & 0.3536 & 0.2110 \\
\hline & & 0.2 & 0.0796 & 0.0708 & 0.3670 & 0.2721 & 0.3690 & 0.2305 \\
\hline & & 0.3 & 0.0747 & 0.1123 & 0.3844 & 0.3138 & 0.4109 & 0.1891 \\
\hline & & 0.4 & 0.0807 & 0.1250 & 0.4092 & 0.3443 & 0.4057 & 0.1943 \\
\hline \multirow[t]{4}{*}{0.5} & 0.6 & 0.1 & 0.0818 & 0.1088 & 0.3545 & 0.2721 & 0.3455 & 0.1545 \\
\hline & & 0.2 & 0.0864 & 0.1187 & 0.3729 & 0.2966 & 0.3408 & 0.1592 \\
\hline & & 0.3 & 0.0918 & 0.1297 & 0.3945 & 0.3240 & 0.3354 & 0.1646 \\
\hline & & 0.4 & 0.0981 & 0.1424 & 0.4201 & 0.3552 & 0.3296 & 0.1704 \\
\hline \multirow[t]{4}{*}{0.4} & 0.6 & 0.1 & 0.0986 & 0.1256 & 0.3633 & 0.2810 & 0.2703 & 0.1297 \\
\hline & & 0.2 & 0.1034 & 0.1356 & 0.3823 & 0.3060 & 0.2652 & 0.1348 \\
\hline & & 0.3 & 0.1090 & 0.1469 & 0.4046 & 0.3341 & 0.2596 & 0.1404 \\
\hline & & 0.4 & 0.1155 & 0.1598 & 0.4310 & 0.3661 & 0.2535 & 0.1465 \\
\hline
\end{tabular}

TABLE 4: The optimal solutions with different value of $\theta$ in the alliance case.

\begin{tabular}{|c|c|c|c|c|c|c|c|}
\hline$T_{0}$ & $\theta$ & $\beta$ & $W_{0}^{*}$ & $P_{1}^{\prime *}$ & $P_{2}^{\prime *}$ & $Q_{1}^{\prime *}$ & $Q_{2}^{\prime *}$ \\
\hline \multirow[t]{4}{*}{0.6} & 0.5 & 0.2 & 0.0896 & 0.3276 & 0.3276 & 0.2796 & 0.2484 \\
\hline & 0.6 & & 0.0896 & 0.3730 & 0.2821 & 0.3250 & 0.2029 \\
\hline & 0.7 & & 0.0896 & 0.4185 & 0.2366 & 0.3705 & 0.1574 \\
\hline & 0.8 & & 0.0896 & 0.4639 & 0.1912 & 0.4159 & 0.1120 \\
\hline \multirow[t]{4}{*}{0.5} & 0.5 & 0.2 & 0.0943 & 0.3302 & 0.3302 & 0.2586 & 0.2414 \\
\hline & 0.6 & & 0.0943 & 0.3756 & 0.2847 & 0.3040 & 0.1960 \\
\hline & 0.7 & & 0.0943 & 0.4211 & 0.2393 & 0.3495 & 0.1505 \\
\hline & 0.8 & & 0.0943 & 0.4665 & 0.1938 & 0.3949 & 0.1051 \\
\hline \multirow[t]{4}{*}{0.4} & 0.5 & 0.2 & 0.1113 & 0.3396 & 0.3396 & 0.1830 & 0.2170 \\
\hline & 0.6 & & 0.1113 & 0.3851 & 0.2942 & 0.2285 & 0.1715 \\
\hline & 0.7 & & 0.1113 & 0.4305 & 0.2487 & 0.2740 & 0.1260 \\
\hline & 0.8 & & 0.1113 & 0.4760 & 0.2032 & 0.3194 & 0.0806 \\
\hline
\end{tabular}

TABLE 5: The optimal solutions with different value of $\beta$ in the alliance case.

\begin{tabular}{|c|c|c|c|c|c|c|c|}
\hline$T_{0}$ & $\theta$ & $\beta$ & $W_{0}^{*}$ & $P_{1}^{\prime *}$ & $P_{2}^{\prime *}$ & $Q_{1}^{\prime *}$ & $Q_{2}^{\prime *}$ \\
\hline \multirow[t]{4}{*}{0.6} & 0.6 & 0.1 & 0.0863 & 0.3562 & 0.2610 & 0.3247 & 0.1884 \\
\hline & & 0.2 & 0.0896 & 0.3730 & 0.2821 & 0.3250 & 0.2029 \\
\hline & & 0.3 & 0.0934 & 0.3925 & 0.3056 & 0.3255 & 0.2188 \\
\hline & & 0.4 & 0.0978 & 0.4153 & 0.3320 & 0.3263 & 0.2364 \\
\hline \multirow[t]{4}{*}{0.5} & 0.6 & 0.1 & 0.0885 & 0.3574 & 0.2621 & 0.3149 & 0.1851 \\
\hline & & 0.2 & 0.0943 & 0.3756 & 0.2847 & 0.3040 & 0.1960 \\
\hline & & 0.3 & 0.1010 & 0.3970 & 0.3101 & 0.2920 & 0.2080 \\
\hline & & 0.4 & 0.1087 & 0.4221 & 0.3388 & 0.2786 & 0.2214 \\
\hline \multirow[t]{4}{*}{0.4} & 0.6 & 0.1 & 0.1053 & 0.3662 & 0.2710 & 0.2397 & 0.1603 \\
\hline & & 0.2 & 0.1113 & 0.3851 & 0.2942 & 0.2285 & 0.1715 \\
\hline & & 0.3 & 0.1182 & 0.4071 & 0.3202 & 0.2162 & 0.1838 \\
\hline & & 0.4 & 0.1261 & 0.4330 & 0.3496 & 0.2025 & 0.1975 \\
\hline
\end{tabular}


retailer $r_{1}$ is larger than the wholesale ticket price to the retailer $r_{2}$.

But when the total amount of cruise tickets ordered by both retailers is constrained by the total number of cruise tickets for the supplier, both retailers' optimal order quantity of cruise tickets should be adjusted based on the existing number of cruise tickets for the supplier, and when $\theta$ is not too large, the wholesale ticket price to the retailer $r_{2}$ is larger than that to the retailer $r_{1}$, and when $\theta$ is relatively large $(\theta=0.8$ in our mode), it is adverse to the former, and the wholesale ticket price to the retailer $r_{1}$ is larger than that to the retailer $r_{2}$. Furthermore, the wholesale prices of the supplier to both retailers in the case in which the total amount of cruise tickets ordered by the two retailers is constrained by the number of cruise tickets for the supplier are larger than that in the case in which the number of cruise tickets for the supplier does not constrain the total amount of cruise tickets ordered by the two retailers. And when $T_{0}=0.5$ and $T_{0}=0.4$, the total amount of cruise tickets ordered by both retailers is constrained by the total number of cruise tickets for the supplier, and the optimal wholesale ticket price to the retailer $r_{1}$ is gradually increasing with the increasing $\theta$, but that to the retailer $r_{2}$ is gradually decreasing with the increasing $\theta$.

From Table 3, we can conclude that the optimal retail ticket prices of both retailers are gradually increasing with the increasing $\beta$ whatever the total number of cruise tickets for the supplier is in the benchmark case, implying that the greater the competition between the two retailers, the higher the retail ticket prices of the two retailers, and when the total number of cruise tickets for the supplier does not constrain the total amount of cruise tickets ordered by the two retailers, both retailers' order quantities of cruise tickets are gradually increasing with the increasing $\beta$ too, and when the total amount of cruise tickets ordered by the two retailers is constrained by the total number of cruise tickets for the supplier, both retailers' optimal order quantities of cruise tickets may be smaller than that in the former, but both retailers' optimal order quantities of cruise tickets are also gradually increasing with the increasing $\beta$. As to the optimal wholesale ticket prices of the supplier, when the total number of cruise tickets for the supplier does not constrain the total amount of cruise tickets ordered by the two retailers, the optimal wholesale ticket prices to both retailers are slightly decreasing with the increasing $\beta$, and the wholesale ticket price to the retailer $r_{1}$, which has the larger market potential, is larger than that to the retailer $r_{2}$. But when the total amount of cruise tickets ordered by the two retailers is constrained by the total number of cruise tickets for the supplier, the wholesale ticket price of supplier to the retailer $r_{2}$ is larger than that to the retailer $r_{1}$. And, under this case, the wholesale ticket prices to both retailers are gradually increasing with the increasing $\beta$, implying that the greater the competition between the two retailers, the higher the wholesale ticket prices of the supplier to both retailers, which is similar to the retail ticket prices of the two retailers. In addition, the wholesale ticket prices of the supplier and the retail ticket prices of the two retailers in a larger number of cruise tickets case are always higher than that in a smaller number of cruise tickets case, which is consistent with [24].
There are the optimal solutions of the supplier and the two retailers in the alliance case in Tables 4-5. From Table 4, we can conclude that the retailer $r_{1}$ 's optimal retail ticket price and the optimal order quantity of cruise tickets are gradually increasing with the increasing $\theta$ under a certain total number of cruise tickets for the supplier; however, the retailer $r_{2}$ 's optimal retail ticket price and the optimal order quantity of cruise tickets are gradually decreasing with the increasing $\theta$ in the alliance case, which is similar to that in the benchmark case. And the optimal wholesale ticket price of the supplier in the alliance case is immunity to the increasing $\theta$, which verifies the previous theoretical result in Corollary 4 . And the optimal wholesale ticket price in a smaller number of cruise tickets case is larger than that in a larger number of numerous cruise tickets' case.

From Table 5, we can conclude that the retail ticket prices of both retailers are gradually increasing with the increasing $\beta$, implying that the greater the competition between the two retailers, the higher the retail ticket prices of both retailers with a certain number of cruise tickets in the alliance case. When the total number of cruise tickets for the supplier does not constrain the total amount of cruise tickets ordered by the two retailers, the two retailers' optimal quantities of cruise tickets are gradually increasing with the increasing $\beta$, implying that the greater the competition between the two retailers, the larger the quantities of cruise tickets ordered by the two retailers. But when the total amount of cruise tickets ordered by the two retailers is constrained by the total number of cruise tickets for the supplier, the optimal order quantity of cruise tickets for the retailer $r_{1}$, which has the relatively larger market potential, is gradually decreasing with the increasing $\beta$, and the optimal order quantity of cruise tickets for the retailer $r_{2}$, which has the relatively smaller market potential, is gradually increasing with the increasing $\beta$. And the wholesale ticket prices of the supplier to both retailers are gradually increasing with the increasing $\beta$ with a certain number of cruise tickets, implying that the greater the competition between the two retailers, the larger the wholesale ticket price of the supplier to both retailers in the alliance case, which is similar to the change in the benchmark case.

5.2. Effects of the Coefficients $\theta$ and $\beta$ on Profits. In this subsection, we study the effects of the coefficients $\theta$ and $\beta$ on the expected profits of the supply chain members and the system in the benchmark case and the alliance case when the total number of cruise tickets for supplier is $T_{0}=0.6$, $T_{0}=0.5$, and $T_{0}=0.4$, respectively.

From Figure 2, we can see that the total expected profits of both retailers are gradually increasing with the increasing $\theta$ and $\beta$ under a certain number of cruise tickets for the supplier condition in two cases. And the larger the total number of cruise tickets, the higher the total expected profits of the two retailers. In fact, it is true that when the total number of cruise tickets for the supplier does not constrain the total amount of cruise tickets ordered by the two retailers, the maximum total expected profit of the two retailers is not changed with the number of cruise tickets for the supplier, because, under this condition, the two retailers have the optimal order quantity 

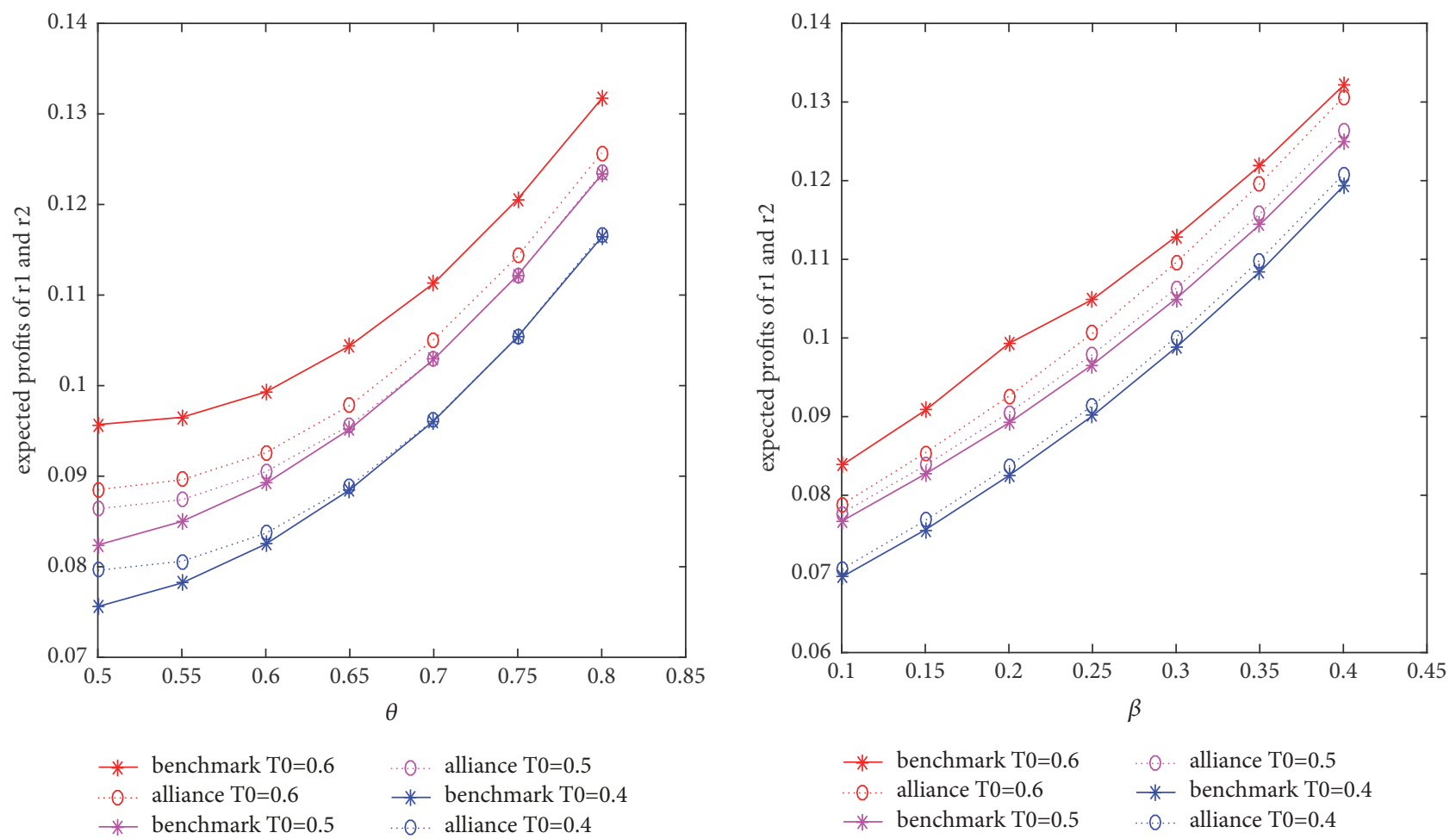

Figure 2: The effect of coefficients $\theta$ and $\beta$ on the total expected profits of the two retailers with different total number of cruise tickets in two cases.

of cruise tickets to maximize their own expected profit, it has nothing to do with the total number of cruise tickets for the supplier, but when the two retailers' total order quantity of cruise tickets is constrained by the total number of cruise tickets for the supplier, it will be the larger the total number of cruise tickets for the supplier, the higher the total expected profit of the two retailers, because the larger total number of cruise tickets can make both retailers obtain more revenue. When the total number of cruise tickets for the supplier equals 0.6 in our model, that means the two retailers' total order quantity of cruise tickets is not constrained by total the number of cruise tickets for the supplier at some times, the total expected profits of the two retailers in the benchmark case are larger than that in the alliance case. However, when the total amount of cruise tickets ordered by the two retailers is constrained by the total number of cruise tickets for the supplier (the total amount of cruise ships for the supplier equals 0.5 and 0.4 in our model), the total expected profits of the two retailers in the alliance case are larger than that in the benchmark case. Furthermore, we can see that the difference value of the total expected profits of the two retailers between the benchmark case and the alliance case is gradually decreasing with the increasing $\theta$, implying that the larger the market potential gap between the two retailers, the total expected profit of the two retailers in the benchmark case is closer to that in the alliance case whether the total expected profits of the two retailers in the benchmark case are larger than that in the alliance case or the total expected profits of the two retailers in the alliance case are larger than that in the benchmark case.
From Figure 3, we can see that the profit of the supplier is hardly affected by the market potential of the retailer $r_{1}(\theta)$ in the alliance case, and the profit of the supplier is increasing and then fluctuates between a fixed value with the increasing $\theta$ when total number of cruise tickets for the supplier equals 0.6 , but the profit of the supplier in the benchmark case is decreasing and then smoothly closer to that in the alliance case when total number of cruise tickets for the supplier equals 0.5 and 0.4 with the increasing $\theta$. Furthermore, the profits of the supplier in the benchmark case and the alliance case are all increasing with the increasing $\beta$ with a certain amount of cruise tickets for the supplier, implying that the greater the competition between the two retailers, the higher the profit of the supplier whether in the benchmark case or in the alliance case. In addition, when the total amount of cruise tickets ordered by the two retailers is constrained by the total number of cruise tickets for the supplier, the profit of the supplier in the benchmark case is higher than that in the alliance case, because the monopoly position of the supplier in the alliance case is weaker than that in the benchmark case, and then the profit of the supplier correspondingly drops. But when the total number of cruise tickets equals 0.6 , it can occur that the profit of the supplier in the alliance case is higher than that in the benchmark case, because the costs of the supplier are increasing with the increasing total number of cruise tickets, and then, for the supplier's monopoly position whether weaker or not, the supplier may put up the wholesale ticket price to the two retailers in order to increase the supplier's incomes, and then the profit of the supplier in the alliance case may be higher than that in the benchmark case; 

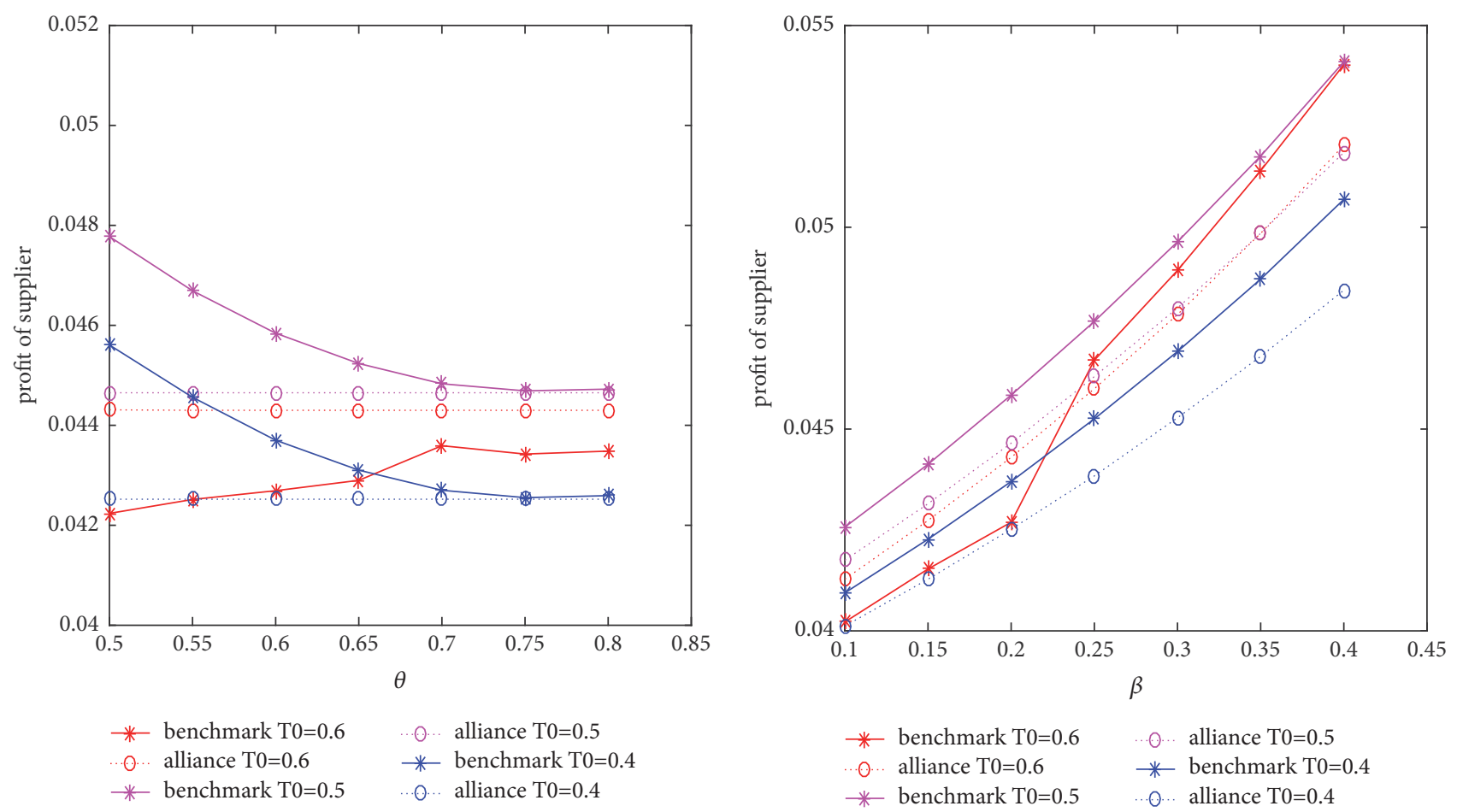

FIGURE 3: The effect of the coefficients $\theta$ and $\beta$ on profit of the supplier with different total number of cruise tickets in two cases.

of course, it may occur that the profit of the supplier in the benchmark case is higher than that in the alliance case when the degree of the competition between the two retailers is relatively large.

From Figure 4, we can see that the profit of the system is gradually increasing with the increasing $\theta$ and $\beta$, and the profit of the system in the benchmark case and the alliance case is almost identical when the total number of cruise tickets equals 0.5 and 0.4 . However, when the total number of cruise tickets equals 0.6 , the profit of the system in the benchmark case is higher than that in the alliance case, which is similar to the change of the two retailers' total expected profits. In addition, the profit of the system in the benchmark case when the total number of cruise tickets equals 0.6 is higher than the other cases with different total number of cruise tickets. In fact, it is not true that the larger the number of cruise tickets, the higher the profit of the system, because the system's profit has something to do with the total quantity of cruise tickets ordered by the two retailers; if the total number of cruise tickets is too larger, the total amount of cruise tickets ordered by the two retailers is not constrained by the total number of cruise tickets for the supplier, the operating costs are increasing, and then the efficiency of the system is lower, which is consistent with Parker and Kapuściński [6] and Chang and Lee et al. [3]. The paper focuses on the difference of the expected profits of the cruise supply chain members and the system between them in the benchmark case and in the alliance case with a certain number of cruise tickets for the supplier; then we do not analyze the effect of the total number of cruise tickets for the supplier.
According to the above analysis, we can give some meaningful management insights for the supply chain members. With a certain number of cruise tickets for the supplier, the performance of the supplier in the benchmark case may outperform that in the alliance case when the total number of cruise tickets for the supplier does not constrain the total amount of cruise tickets ordered by the two retailers. It is good for the two retailers to have a virtual alliance, combining to form one retailer when the total amount of cruise tickets ordered by the two retailers is constrained by the total number of cruise tickets for the supplier, but when the total number of cruise tickets for the supplier does not constrain the total amount of cruise tickets ordered by the two retailers, it is not good for the two retailers to launch a virtual alliance to form one retailer.

\section{Conclusion}

In this paper, the two-echelon cruise tourism supply chain with one supplier and two competing retailers which are in the same competing market is investigated, and we model a decentralized system with limited total number of cruise tickets for the supplier and stochastic demand. We investigate the optimal decisions of the supplier and the two retailers using the supplier Stackelberg game in two different cases with a certain number of cruise tickets. First, the benchmark case: the supplier properly sets the wholesale ticket prices to the two retailers differently, and the two retailers determine the optimal decisions following a policy similar to the "basestock" policy. Second, the alliance case: the two retailers launch a virtual alliance, combining to one retailer, and the 

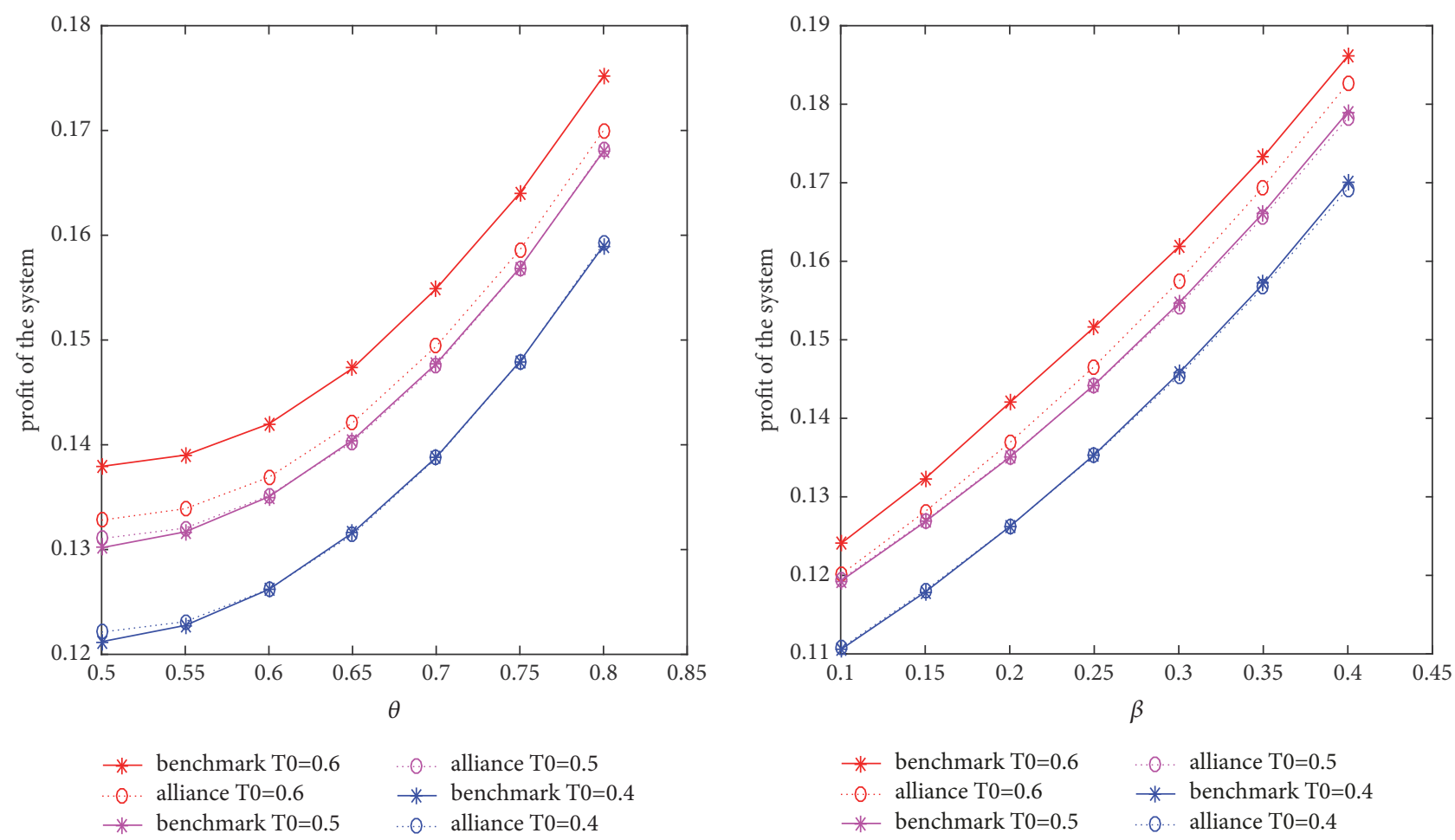

FIgURE 4: The effect of the coefficients $\theta$ and $\beta$ on profit of the system with different total number of cruise tickets in two cases.

supplier sets the uniform wholesale price to the two retailers, and the two retailers determine the optimal decisions in this case using the same method in the benchmark case. And, in a numerical example, we can find that the size relationship of the wholesale ticket prices between them in the benchmark case and in the alliance case is not determined; it is related to the total number of cruise tickets for the supplier, cross-price coefficient, the reorder costs, and some other factors.

Furthermore, the larger the market potential of the retailer, the larger the retailer's retail ticket price and the order quantity of cruise tickets; the retail ticket prices of both retailers are increasing with the increasing cross-price coefficient. The wholesale ticket price of the supplier in the alliance case is not affected by the market potential of the two retailers, but it is increasing with the increasing crossprice coefficient. In addition, it is better off for the two retailers to launch a virtual alliance when the total amount of cruise tickets orders of the two retailers is constrained by the total number of cruise tickets for the supplier, but the total expected profits of both retailers in the alliance case are smaller than that in the benchmark case when the total number of cruise tickets for the supplier does not constrain the total amount of cruise tickets ordered by the two retailers. The supplier will put up the wholesale ticket price in the alliance case, and that increases the supplier's incomes to offset the costs, and the profit of the system in the alliance case is close to that in the benchmark case when the total amount of cruise tickets ordered by the two retailers is constrained by the total number of cruise tickets for the supplier, but the profit of the system in the alliance case is smaller than that in the benchmark case when the total number of cruise tickets for the supplier does not constrain the total amount of cruise tickets ordered by the two retailers.

Certainly, there are some limitations in this paper. First, we assume that the cruise supply chain members are riskneutral, but that may not be true in reality. Second, the two retailers' demands are assumed to be uniformly distributed, and a future analysis would be to study the random demands of the two retailers with a general distribution. Finally, the full ticket prices or the non-full ticket prices buyback contract of the cruise supply chain would be another significant analysis.

\section{Appendix}

Proof of Proposition 1. First, we give the proof of formula (11).

Take the first derivative $\Pi r_{i}\left(P_{i}, z_{i}\right)$ with respect to $P_{i}, z_{i}$, respectively, and we have

$$
\begin{aligned}
& \frac{\partial \Pi r_{1}}{\partial p_{1}}=-2 p_{1}+\beta p_{2}+w_{1}+\theta, \\
& \frac{\partial \Pi r_{2}}{\partial p_{2}}=-2 p_{2}+\beta p_{1}+w_{2}+1-\theta, \\
& \frac{\partial \Pi r_{1}}{\partial z_{1}}=-w_{1}+g-g * F_{1}\left(z_{1}\right), \\
& \frac{\partial \Pi r_{2}}{\partial z_{2}}=-w_{2}+g-g * F_{2}\left(z_{2}\right),
\end{aligned}
$$


Take the second derivative $\Pi r_{i}\left(P_{i}, z_{i}\right)$ with respect to $P_{i}, z_{i}$, respectively, and we have

$$
\begin{aligned}
& \frac{\partial^{2} \Pi r_{i}\left(P_{i}, z_{i}\right)}{\partial P_{i}^{2}}=-2 \\
& \frac{\partial^{2} \Pi r_{i}\left(P_{i}, z_{i}\right)}{\partial P_{i} \partial z_{i}}=\frac{\partial^{2} \Pi r_{i}\left(P_{i}, z_{i}\right)}{\partial z_{i} \partial P_{i}}=0 \\
& \frac{\partial^{2} \Pi r_{i}\left(P_{i}, z_{i}\right)}{\partial z_{i}^{2}}=-g * f_{i}\left(z_{i}\right)
\end{aligned}
$$

$$
(i=1,2)
$$

For the given values of $W_{1}$ and $W_{2}$, we have Hessian matrix as follows:

$$
H_{i}(1)=\left[\begin{array}{cc}
-2 & 0 \\
0 & -g f_{i}\left(z_{i}\right)
\end{array}\right], \quad(i=1,2)
$$

due to $-2<0$,

$$
\left|\begin{array}{cc}
-2 & 0 \\
0 & -g f_{i}\left(z_{i}\right)
\end{array}\right|=2 g f_{i}\left(z_{i}\right)>0
$$

The Hessian matrix is negative definite, so $\Pi r_{i}\left(P_{i}, z_{i}\right)$ is concave on the vector $\left(P_{i}, z_{i}\right)(i=1,2)$.

Let the first order of $\Pi r_{i}\left(P_{i}, z_{i}\right),(i=1,2)$ with respect to $P_{i}, z_{i}$ equal 0 , and, by solving the simultaneous equation, we can obtain (11).

Then, from (11), we have

$$
\begin{aligned}
& \frac{\partial P_{1}}{\partial \beta}=\frac{\left(W_{2}+1-\theta\right)\left(4-\beta^{2}\right)+2 \beta I_{1}}{\left(4-\beta^{2}\right)^{2}} \\
& \frac{\partial P_{2}}{\partial \beta}=\frac{\left(W_{1}+\theta\right)\left(4-\beta^{2}\right)+2 \beta I_{2}}{\left(4-\beta^{2}\right)^{2}}
\end{aligned}
$$

where $I_{1}=2 W_{1}+\beta W_{2}+\beta+(2-\beta) \theta, I_{2}=2 W_{2}+\beta W_{1}+\beta+$ $(2-\beta)(1-\theta)$. 0 .

Since $I_{i}>0, i=1,2$, it follows that $\partial P_{1} / \partial \beta>0, \partial P_{2} / \partial \beta>$
Then we have the retail ticket prices of the two retailers that are increasing with the increasing intensity of competition between the two retailers.

Proof of Proposition 2. From (10), we can formulate a model for the profit function of the supplier as follows:

$$
\begin{array}{ll} 
& \Pi_{s}\left(W_{1}, W_{2}\right)=W_{1} Q_{1}+W_{2} Q_{2}-c T_{0} \\
\text { s.t. } & Q_{1}+Q_{2} \leq T_{0} \\
& W_{i} \geq 0, \quad i=1,2 .
\end{array}
$$

Substituting $Q_{1}^{*}, Q_{2}^{*}$ in (11) into the above expression, we can construct the Lagrange function as follows:

$$
\begin{aligned}
L= & L\left(W_{1}, W_{2}, \lambda\right)=R\left(W_{1}, W_{2}\right) \\
& +\lambda\left(T_{0}-r\left(W_{1}, W_{2}\right)\right) \\
\text { s.t. } & \frac{\left(\beta^{2}+\beta-2\right)\left(W_{1}+W_{2}\right)+2+\beta}{4-\beta^{2}} \\
& +F_{1}^{-1}\left(\frac{g-W_{1}}{g}\right)+F_{2}^{-1}\left(\frac{g-W_{2}}{g}\right) \leq T_{0} \\
& \quad W_{i} \geq 0, i=1,2
\end{aligned}
$$

where $R\left(W_{1}, W_{2}\right)=\Pi_{s}\left(W_{1}, W_{2}\right)$,

$$
\begin{aligned}
r\left(W_{1}, W_{2}\right)= & \frac{\left(\beta^{2}+\beta-2\right)\left(W_{1}+W_{2}\right)+2+\beta}{4-\beta^{2}} \\
& +F_{1}^{-1}\left(\frac{g-W_{1}}{g}\right)+F_{2}^{-1}\left(\frac{g-W_{2}}{g}\right) .
\end{aligned}
$$

Take the second derivative $\Pi s\left(W_{1}, W_{2}\right)$ with respect to $W_{1}, W_{2}$, respectively, and we have the Hessian matrix

$H(2)$

$$
=\left[\begin{array}{cc}
\frac{\left(2 \beta^{2}-4\right) g^{2} f_{1}^{3}}{\left(4-\beta^{2}\right) g^{2} f_{1}^{3}}-X_{1} & \frac{2 \beta}{4-\beta^{2}} \\
\frac{2 \beta}{4-\beta^{2}} & \frac{\left(2 \beta^{2}-4\right) g^{2} f_{2}^{3}}{\left(4-\beta^{2}\right) g^{2} f_{2}^{3}}-X_{2}
\end{array}\right]
$$

where $X_{1}=\left(2\left(4-\beta^{2}\right) g f_{1}^{2}+\left(4-\beta^{2}\right) f_{1}^{\prime} W_{1}\right) /\left(4-\beta^{2}\right) g^{2} f_{1}^{3}$ and $X_{2}=\left(2\left(4-\beta^{2}\right) g f_{2}^{2}+\left(4-\beta^{2}\right) f_{2}^{\prime} W_{2}\right) /\left(4-\beta^{2}\right) g^{2} f_{2}^{3}$.

Due to $\partial^{2} \Pi_{s}\left(W_{1}, W_{2}\right) / \partial W_{1}^{2}=\left(2 \beta^{2}-4\right) g^{2} f_{1}^{3} /(4-$ $\left.\beta^{2}\right) g^{2} f_{1}^{3}-X_{1}<0$,

$$
|H(2)|=\frac{\left[\left(2 \beta^{2}-4\right) g^{2} f_{1}^{3}-X_{1}\right] *\left[\left(2 \beta^{2}-4\right) g^{2} f_{2}^{3}-X_{2}\right]-4 \beta^{2} g^{4} f_{1}^{3} f_{2}^{3}}{\left(4-\beta^{2}\right)^{2} g^{4} f_{1}^{3} f_{2}^{3}}>0 .
$$

The Hessian matrix is negative definite, so $\Pi s\left(W_{1}, W_{2}\right)$ is joint concave with respect to $W_{1}$ and $W_{2}$; say, $R\left(W_{1}, W_{2}\right)$ is joint concave with respect to $W_{1}, W_{2}$, so we can use the K-T conditions to discuss it in two cases. 
(i) $\lambda=0$, and we have $W_{1}>0, W_{2}>0$, and

$$
\begin{aligned}
\frac{\partial L}{\partial W_{1}} & =\frac{\partial R}{\partial W_{1}}-0 * \frac{\partial r}{\partial W_{1}}=0 \\
\frac{\partial L}{\partial W_{2}} & =\frac{\partial R}{\partial W_{2}}-0 * \frac{\partial r}{\partial W_{2}}=0 \\
\frac{\partial L}{\partial \lambda} & =T_{0}-r\left(W_{1}, W_{2}\right) \geq 0 ;
\end{aligned}
$$

i.e.,

$$
\begin{aligned}
& \frac{\left(\beta^{2}-2\right) W_{1}+\beta W_{2}+\beta+(2-\beta) \theta}{4-\beta^{2}}+W_{1} \\
& *\left(\frac{\beta^{2}-2}{4-\beta^{2}}-\frac{1}{g f_{1}}\right)+W_{2} * \frac{\beta}{4-\beta^{2}} \\
& +F_{1}^{-1}\left(\frac{g-W_{1}}{g}\right)=0 \\
& \frac{\left(\beta^{2}-2\right) W_{2}+\beta W_{1}+\beta+(2-\beta)(1-\theta)}{4-\beta^{2}}+W_{2} \\
& *\left(\frac{\beta^{2}-2}{4-\beta^{2}}-\frac{1}{g f_{2}}\right)+W_{1} * \frac{\beta}{4-\beta^{2}} \\
& +F_{2}^{-1}\left(\frac{g-W_{2}}{g}\right)=0 \\
& \quad\left(\beta^{2}+\beta-2\right)\left(W_{1}+W_{2}\right)+2+\beta \\
& \left.T_{0}-\frac{\beta^{2}}{g}\right)-F_{2}^{-1}\left(\frac{g-W_{2}}{g}\right) \geq 0 .
\end{aligned}
$$

Then we can calculate it and have the optimal solution (12).

(ii) $\lambda>0$, and we have $W_{1}>0, W_{2}>0$, and

$$
\begin{aligned}
\frac{\partial L}{\partial W_{1}} & =\frac{\partial R}{\partial W_{1}}-\lambda \frac{\partial r}{\partial W_{1}}=0 \\
\frac{\partial L}{\partial W_{2}} & =\frac{\partial R}{\partial W_{2}}-\lambda \frac{\partial r}{\partial W_{2}}=0 \\
\frac{\partial L}{\partial \lambda} & =T_{0}-r\left(W_{1}, W_{2}\right)=0 ;
\end{aligned}
$$

i.e.,

$$
\begin{aligned}
& \frac{\left(\beta^{2}-2\right) W_{1}+\beta W_{2}+\beta+(2-\beta) \theta}{4-\beta^{2}}+W_{1} \\
& *\left(\frac{\beta^{2}-2}{4-\beta^{2}}-\frac{1}{g f_{1}}\right)+W_{2} * \frac{\beta}{4-\beta^{2}} \\
& +F_{1}^{-1}\left(\frac{g-W_{1}}{g}\right)-\lambda\left(\frac{\beta^{2}+\beta-2}{4-\beta^{2}}-\frac{1}{g f_{1}}\right)=0
\end{aligned}
$$

$$
\begin{aligned}
& \frac{\left(\beta^{2}-2\right) W_{2}+\beta W_{1}+\beta+(2-\beta)(1-\theta)}{4-\beta^{2}}+W_{2} \\
& *\left(\frac{\beta^{2}-2}{4-\beta^{2}}-\frac{1}{g f_{2}}\right)+W_{1} * \frac{\beta}{4-\beta^{2}} \\
& +F_{2}^{-1}\left(\frac{g-W_{2}}{g}\right)-\lambda\left(\frac{\beta^{2}+\beta-2}{4-\beta^{2}}-\frac{1}{g f_{2}}\right)=0 \\
& T_{0}-\frac{\left(\beta^{2}+\beta-2\right)\left(W_{1}+W_{2}\right)+2+\beta}{4-\beta^{2}} \\
& -F_{1}^{-1}\left(\frac{g-W_{1}}{g}\right)-F_{2}^{-1}\left(\frac{g-W_{2}}{g}\right)=0 .
\end{aligned}
$$

Then we can calculate it and have the optimal solution (13).

Proof of Proposition 3 . The structure in the alliance case is the same as that in the benchmark case, and we can have that $\Pi^{\prime} s\left(W_{0}\right)$ is concave in $W_{0}$.

Then we use the same method in Proof of Proposition 2 to discuss it in two cases.

(i) $\lambda=0$, and we have

$$
\begin{gathered}
\left(\frac{4 \beta^{2}+4 \beta-8}{4-\beta^{2}}-\frac{1}{g f_{1}}-\frac{1}{g f_{2}}\right) W_{0}+\frac{1}{2-\beta} \\
+F_{1}^{-1}\left(\frac{g-W_{0}}{g}\right)+F_{2}^{-1}\left(\frac{g-W_{0}}{g}\right)=0 \\
T_{0}-\frac{\left(2 \beta^{2}+2 \beta-4\right) W_{0}+(2+\beta)}{4-\beta^{2}} \\
-F_{1}^{-1}\left(\frac{g-W_{0}}{g}\right)-F_{2}^{-1}\left(\frac{g-W_{0}}{g}\right) \geq 0 .
\end{gathered}
$$
(18).

(ii) $\lambda>0$, and we have

$$
\begin{gathered}
\left(\frac{4 \beta^{2}+4 \beta-8}{4-\beta^{2}}-\frac{1}{g f_{1}}-\frac{1}{g f_{2}}\right) W_{0}+\frac{1}{2-\beta} \\
+F_{1}^{-1}\left(\frac{g-W_{0}}{g}\right)+F_{2}^{-1}\left(\frac{g-W_{0}}{g}\right) \\
-\lambda\left(\frac{2 \beta^{2}+2 \beta-4}{4-\beta^{2}}-\frac{1}{g f_{1}}-\frac{1}{g f_{2}}\right)=0 \\
T_{0}-\frac{\left(2 \beta^{2}+2 \beta-4\right) W_{0}+(2+\beta)}{4-\beta^{2}} \\
-F_{1}^{-1}\left(\frac{g-W_{0}}{g}\right)-F_{2}^{-1}\left(\frac{g-W_{0}}{g}\right)=0 .
\end{gathered}
$$


Then we can calculate it and have the optimal solution (19).

Proof of Corollary 4. From Proposition 3, we know that the optimal wholesale price of the supplier in the alliance case can be expressed as (18) and (19), and we define (18) and (19) as $A_{1}\left(W_{0}\right)$ and $A_{2}\left(W_{0}\right)$ and differentiate $A_{1}\left(W_{0}\right)$ and $A_{2}\left(W_{0}\right)$ with respect to $W_{0}, \theta$, respectively, using the derivative of the implicit function, and we have $\partial \mathrm{W}_{0} / \partial \theta=0$, that completes this proof.

\section{Data Availability}

The data used to support the findings of this study are available from the corresponding author upon request.

\section{Conflicts of Interest}

The authors declare that they have no conflicts of interest.

\section{Acknowledgments}

The authors gratefully acknowledge the support from the National Natural Science Foundation of China through Grant 71571117 and Shanghai Key Basic Research Program through Grant 15590501800.

\section{References}

[1] X. Sun, Y. Jiao, and P. Tian, "Marketing research and revenue optimization for the cruise industry: A concise review," International Journal of Hospitality Management, vol. 30, no. 3, pp. 746-755, 2011.

[2] X. Sun, X. Feng, and D. K. Gauri, "The cruise industry in China: Efforts, progress and challenges," International Journal of Hospitality Management, vol. 42, pp. 71-84, 2014.

[3] Y.-T. Chang, S. Lee, and H. Park, "Efficiency analysis of major cruise lines," Tourism Management, vol. 58, pp. 78-88, 2017.

[4] Y.-T. Chang, H. Park, S.-M. Liu, and Y. Roh, "Economic impact of cruise industry using regional input-output analysis: a case study of Incheon," Maritime Policy \& Management, vol. 43, no. 1, pp. 1-18, 2016.

[5] R. Zhang and B. Liu, "Group buying decisions of competing retailers with emergency procurement," Annals of Operations Research, vol. 257, no. 1-2, pp. 317-333, 2017.

[6] R. P. Parker and R. Kapuściński, "Managing a noncooperative supply chain with limited capacity," Operations Research, vol. 59, no. 4, pp. 866-881, 2011.

[7] T. M. Whitin, "Inventory control and price theory," Management Science, vol. 2, no. 1, pp. 61-68, 1955.

[8] N. C. Petruzzi and M. Dada, "Pricing and the newsvendor problem: a review with extensions," Operations Research, vol. 47, no. 2, pp. 183-194, 1999.

[9] G. W. Hua, S. Y. Wang, and T. C. E. Cheng, "Optimal pricing and order quantity for the newsvendor problem with free shipping," International Journal of Production Economics, vol. 135, no. 1, pp. 162-169, 2012.

[10] H. Fu, B. Dan, and X. Sun, "Joint optimal pricing and ordering decisions for seasonal products with weather-sensitive demand," Discrete Dynamics in Nature and Society, vol. 2014, Article ID 105098, 2014.

[11] X. Wu and J. Zhang, "Joint ordering and pricing decisions for new repeat-purchase products," Discrete Dynamics in Nature and Society, vol. 2015, Article ID 461959, 2015.

[12] B. Liu, R. Zhang, and M. Xiao, "Joint decision on production and pricing for online dual channel supply chain system," Applied Mathematical Modelling: Simulation and Computation for Engineering and Environmental Systems, vol. 34, no. 12, pp. 4208-4218, 2010.

[13] X. Tiaojun, Y. Gang, S. Zhaohan, and X. Yusen, "Coordination of a Supply Chain with One-Manufacturer and Two-Retailers Under Demand Promotion and Disruption Management Decisions," Annals of Operations Research, vol. 135, pp. 87-109, 2005.

[14] G. P. Cachon and P. H. Zipkin, "Competitive and cooperative inventory policies in a two-stage supply chain," Management Science, vol. 45, no. 7, pp. 936-953, 1999.

[15] Q. Qi, J. Wang, and Q. Bai, "Pricing decision of a two-echelon supply chain with one supplier and two retailers under a carbon cap regulation," Journal of Cleaner Production, vol. 151, pp. 286302, 2017

[16] G. Parthasarathi, S. P. Sarmah, and M. Jenamani, "Supply chain coordination under retail competition using stock dependent price-setting newsvendor framework," Operational Research, vol. 11, no. 3, pp. 259-279, 2010.

[17] F. Bernstein and A. Federgruen, "Decentralized supply chains with competing retailers under demand uncertainty," Management Science, vol. 51, no. 1, pp. 18-29, 2005.

[18] V. G. Narayanan, A. Raman, and J. Singh, "Agency costs in a supply chain with demand uncertainty and price competition," Management Science, vol. 51, no. 1, pp. 120-132, 2005.

[19] A. Federgruen and P. Zipkin, "An inventory model with limited production capacity and uncertain demands. I. The averagecost criterion," Mathematics of Operations Research, vol. 11, no. 2, pp. 193-207, 1986.

[20] M. Ben Daya and A. Raouf, "On the Constrained Multiitem Single-period Inventory Problem," International Journal of Operations \& Production Management, vol. 13, no. 11, pp. 104$112,1993$.

[21] B. Zhang, "Multi-tier binary solution method for multi-product newsvendor problem with multiple constraints," European Journal of Operational Research, vol. 218, no. 2, pp. 426-434, 2012.

[22] C. Selcuk and B. Gokpinar, "Fixed vs. Flexible Pricing in a Competitive Market," Management Science, 2018.

[23] S. Luo, S. P. Sethi, and R. Shi, "On the optimality conditions of a price-setting newsvendor problem," Operations Research Letters, vol. 44, no. 6, pp. 697-701, 2016.

[24] H.-M. Teng, P.-H. Hsu, and H.-M. Wee, "An optimization model for products with limited production quantity," Applied Mathematical Modelling: Simulation and Computation for Engineering and Environmental Systems, vol. 39, no. 7, pp. 1867-1874, 2015. 


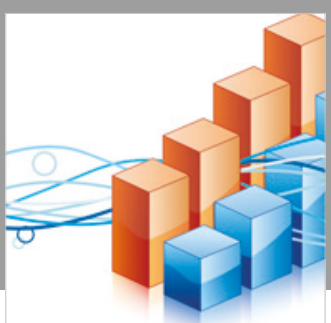

Advances in

Operations Research

\section{-n-m}
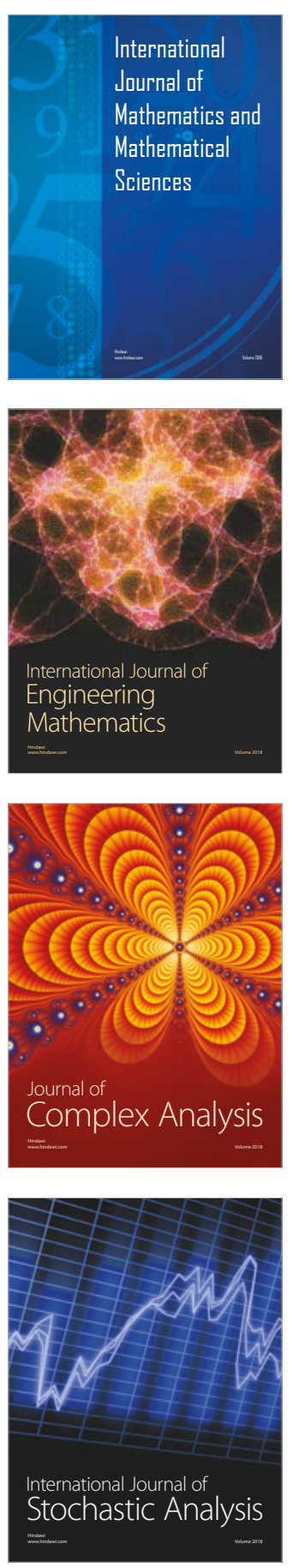
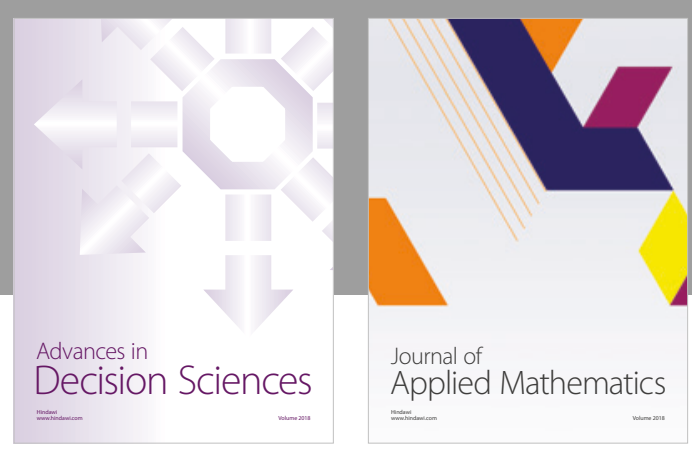

Journal of

Applied Mathematics
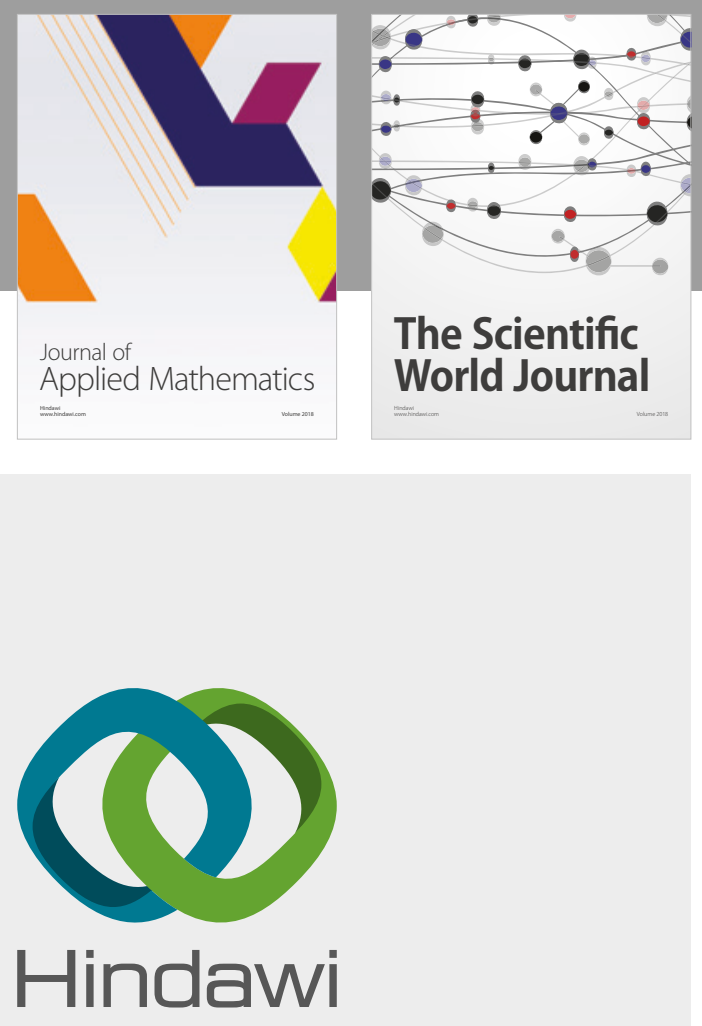

Submit your manuscripts at

www.hindawi.com

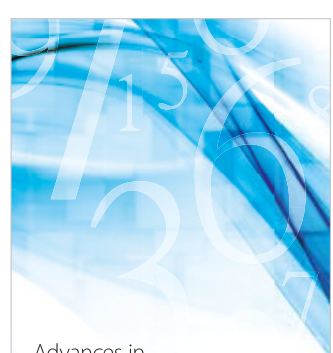

Advances in
Numerical Analysis
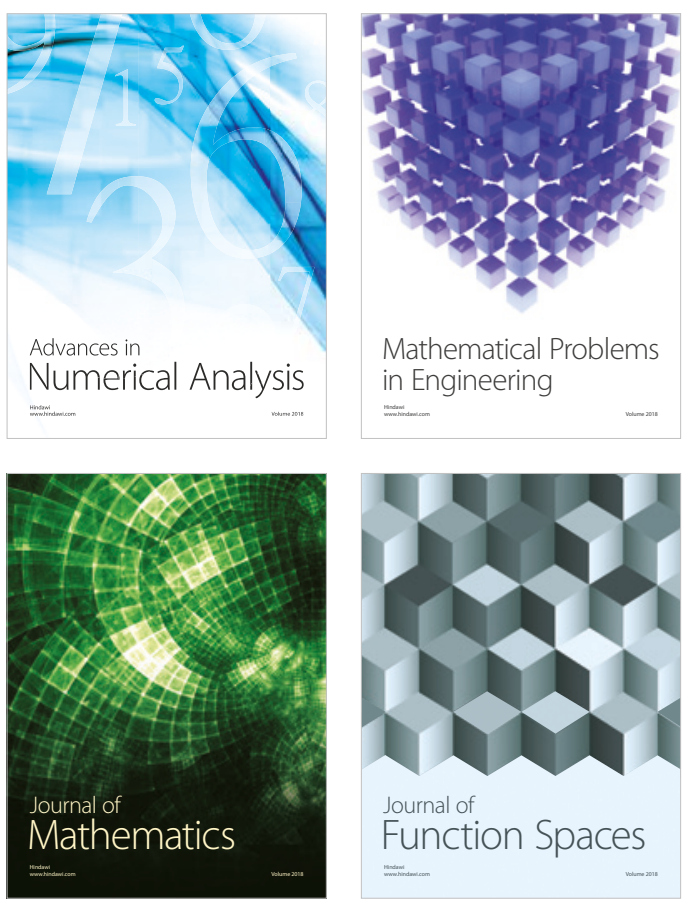

Mathematical Problems in Engineering

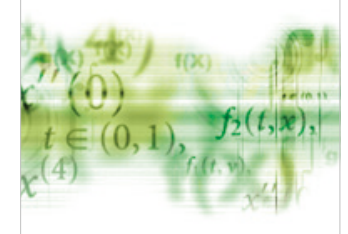

International Journal of

Differential Equations

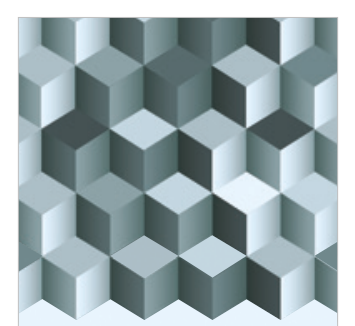

Journal of

Function Spaces

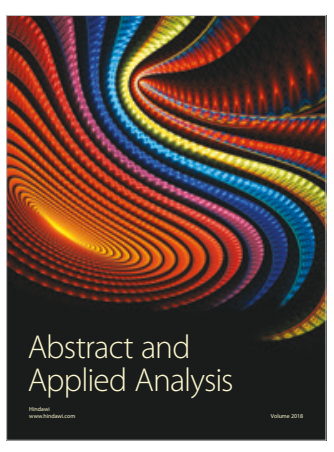

The Scientific

World Journal

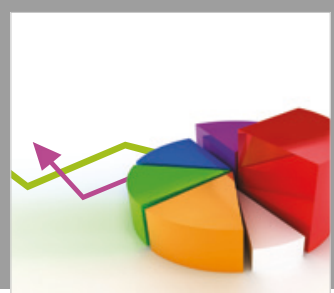

Journal of

Probability and Statistics
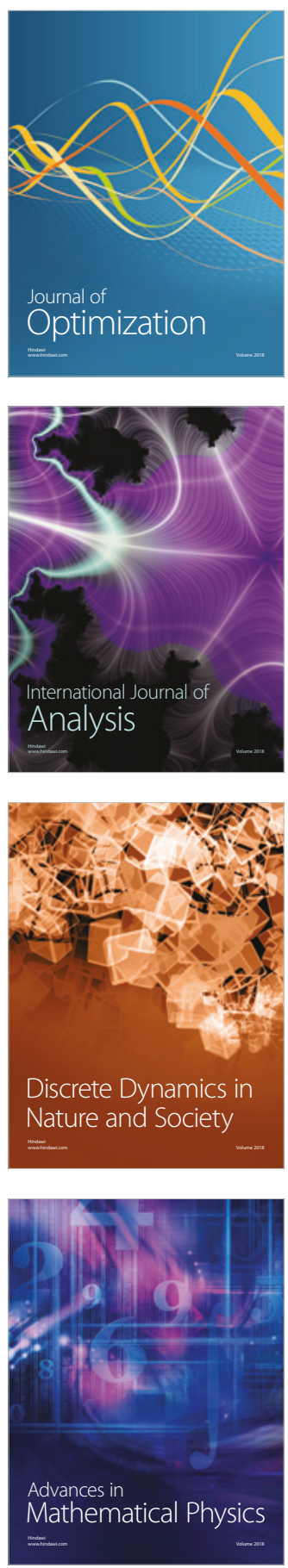